\title{
Total Synthesis of the Plant Growth Promoter Auxofuran featuring a Gold(I) catalyzed Furan Formation
}

Sibylle Riedel ${ }^{\dagger}$ and Martin E. Maier ${ }^{*}+$

${ }^{\dagger}$ Eberhard Karls Universität Tübingen, Institut für Organische Chemie, Auf der Morgenstelle 18, 72076 Tübingen, Germany

martin.e.maier@uni-tuebingen.de

\section{Contents}

Copies of NMR spectra 


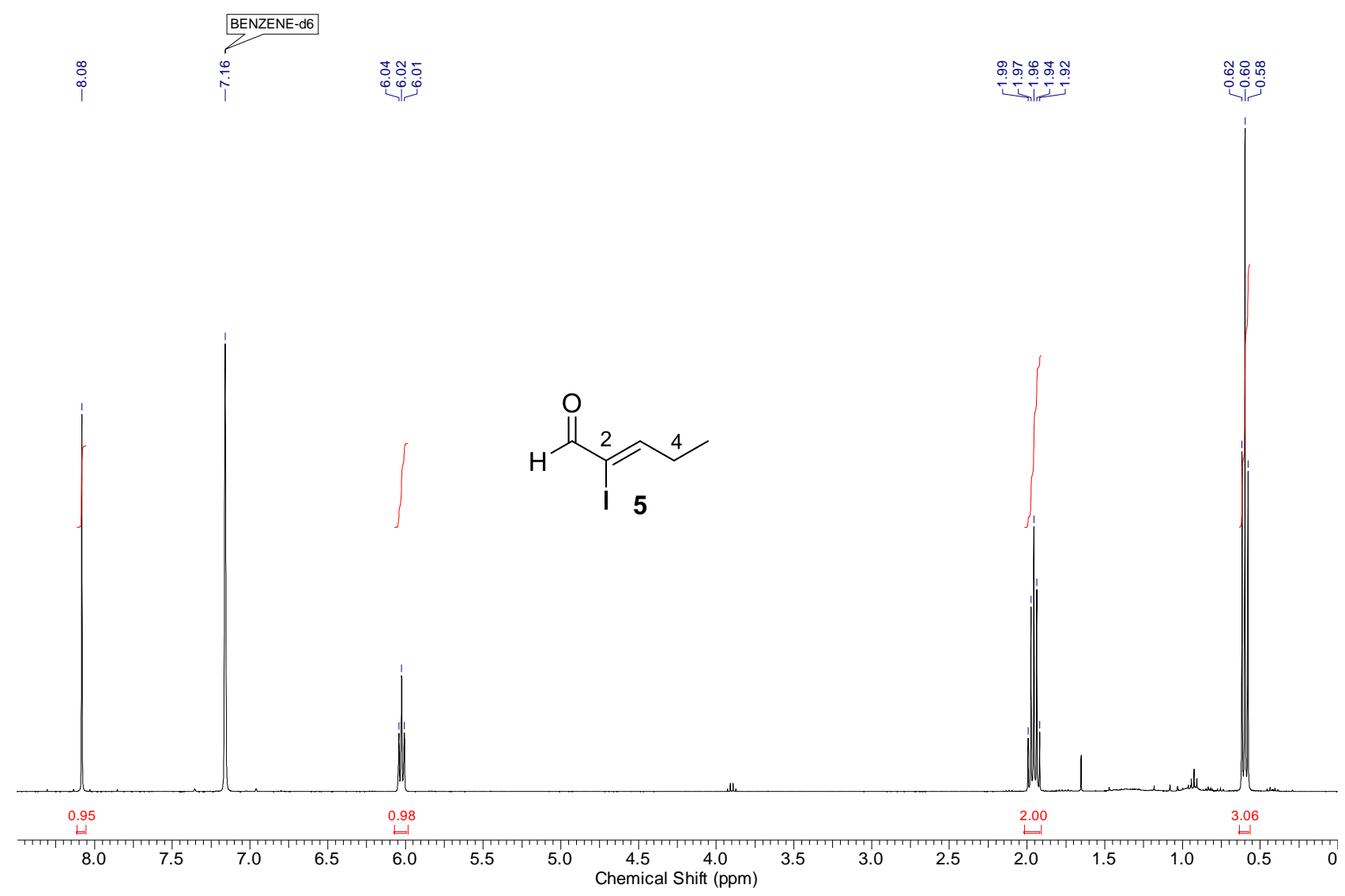

${ }^{1} \mathrm{H}$ NMR $(400 \mathrm{MHz})$ spectrum of iodopentenal 5 in $\mathrm{C}_{6} \mathrm{D}_{6}(0.5-8.5 \mathrm{ppm})$

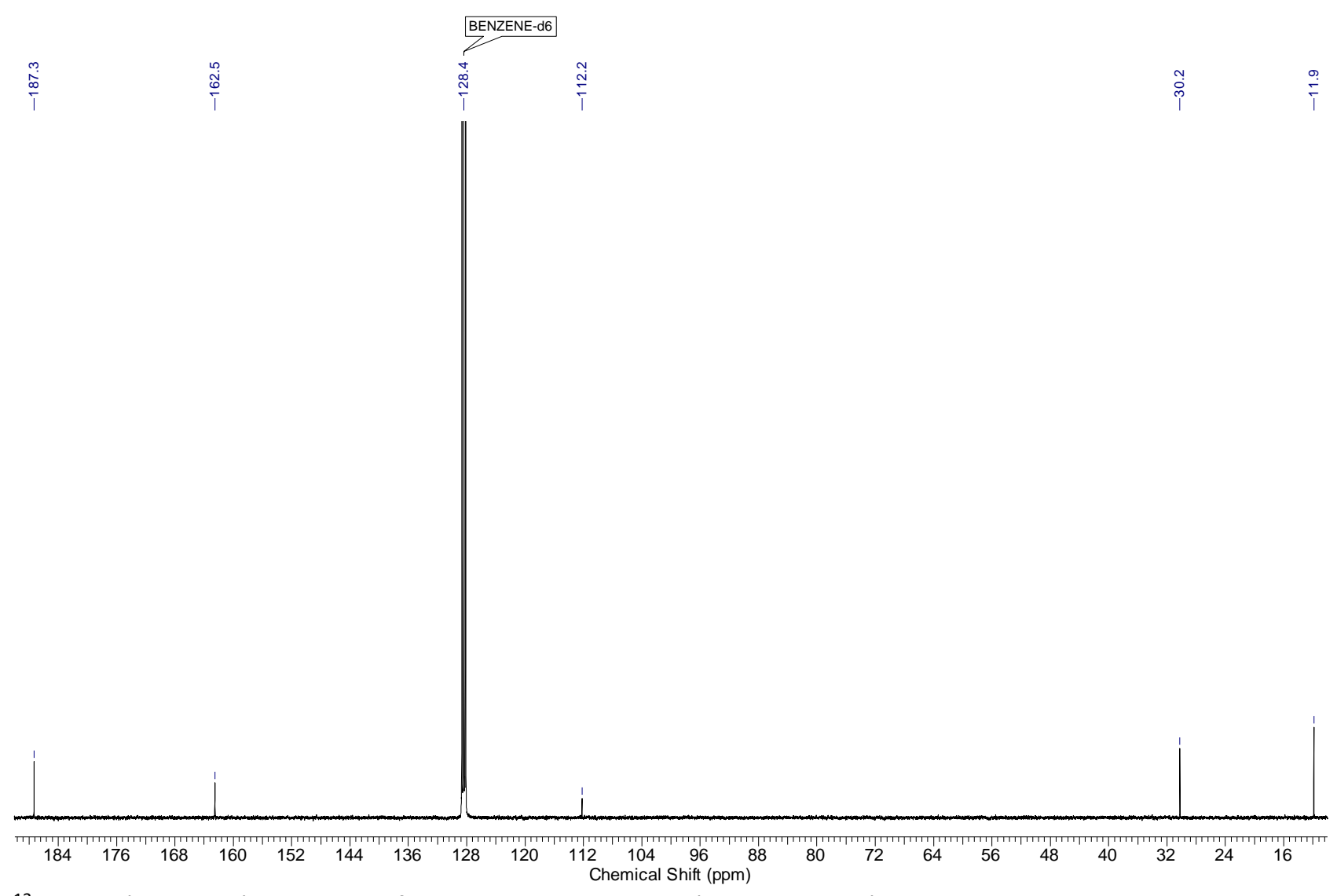

${ }^{13} \mathrm{C}$ NMR (100 MHz) spectrum of iodopentenal 5 in $C_{6} D_{6}(10-190 \mathrm{ppm})$ 


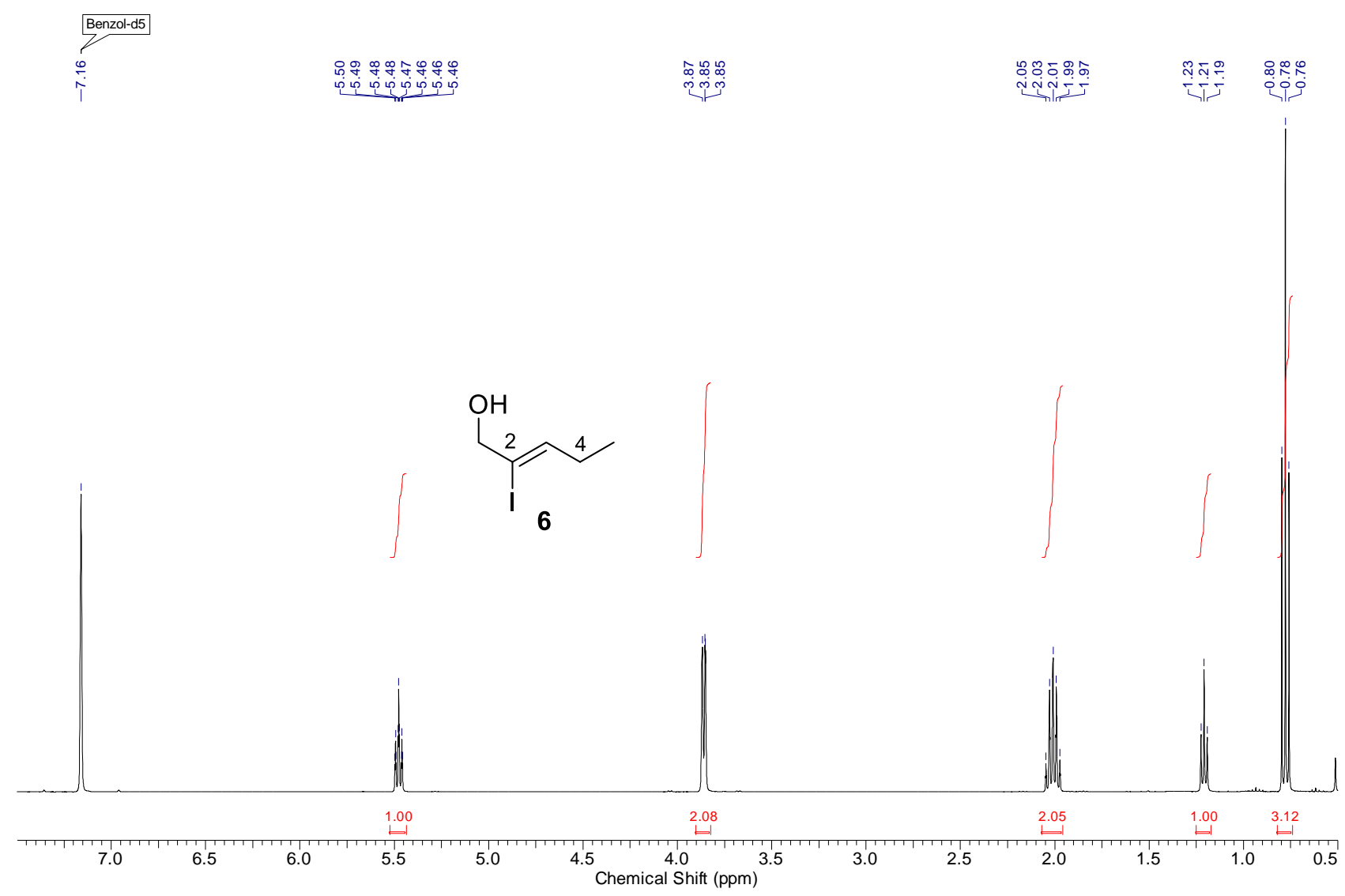

${ }^{1} \mathrm{H} \mathrm{NMR}(400 \mathrm{MHz})$ spectrum of iodopentenol 6 in $\mathrm{C}_{6} \mathrm{D}_{6}(0.5-7.5 \mathrm{ppm})$

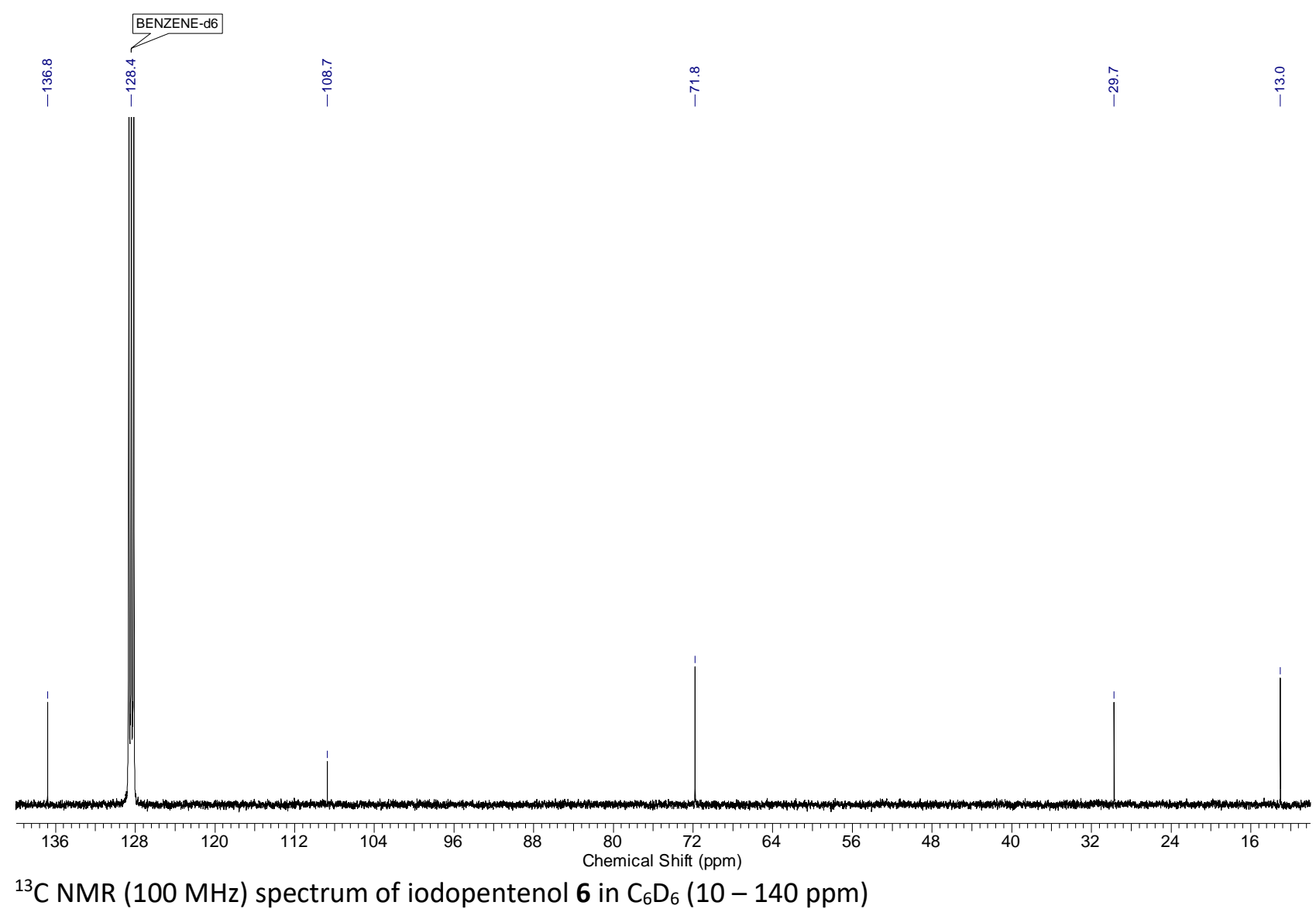




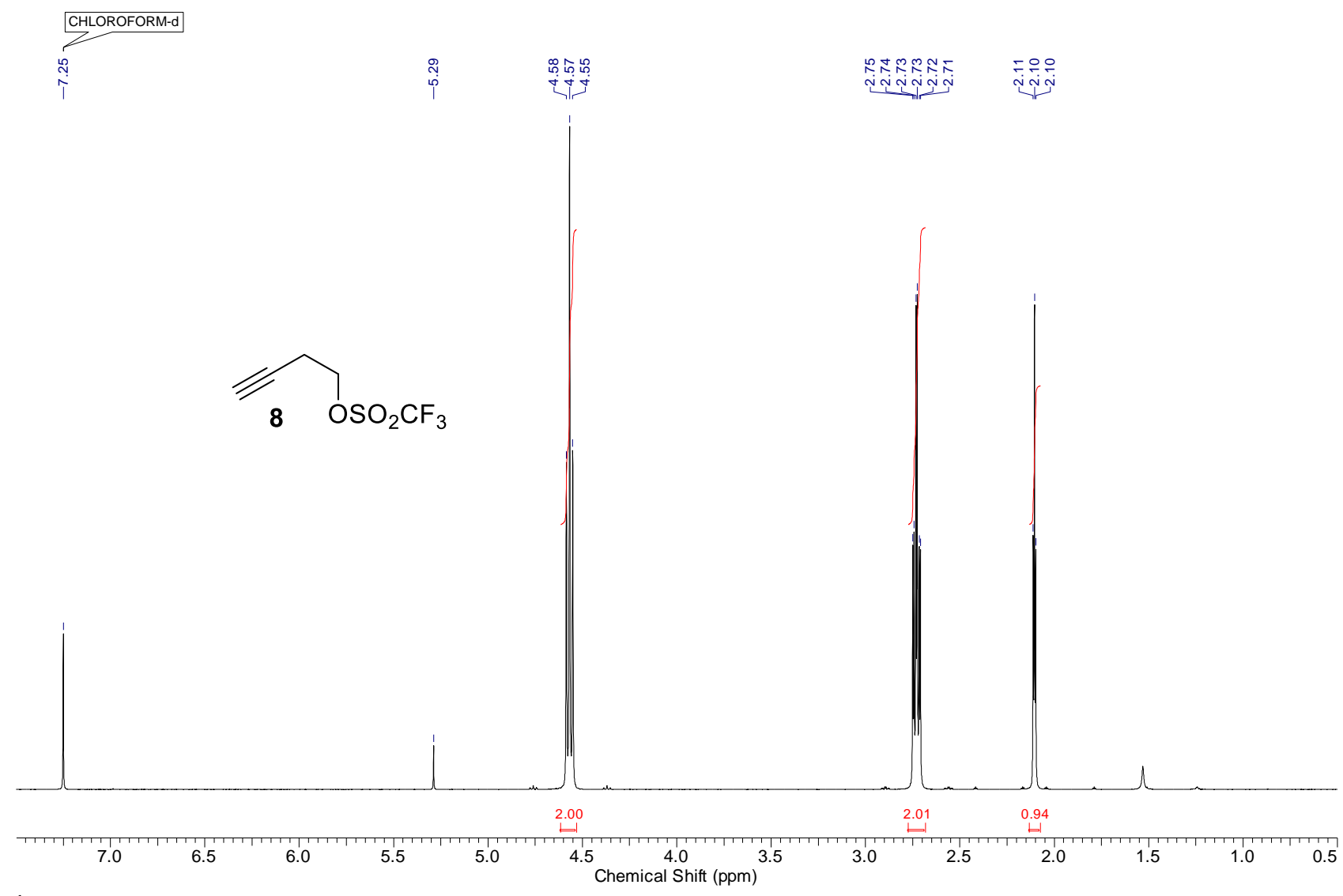

${ }^{1} \mathrm{H} \mathrm{NMR}(400 \mathrm{MHz})$ spectrum of triflate 8 in $\mathrm{CDCl}_{3}(0.5-7.5 \mathrm{ppm})$

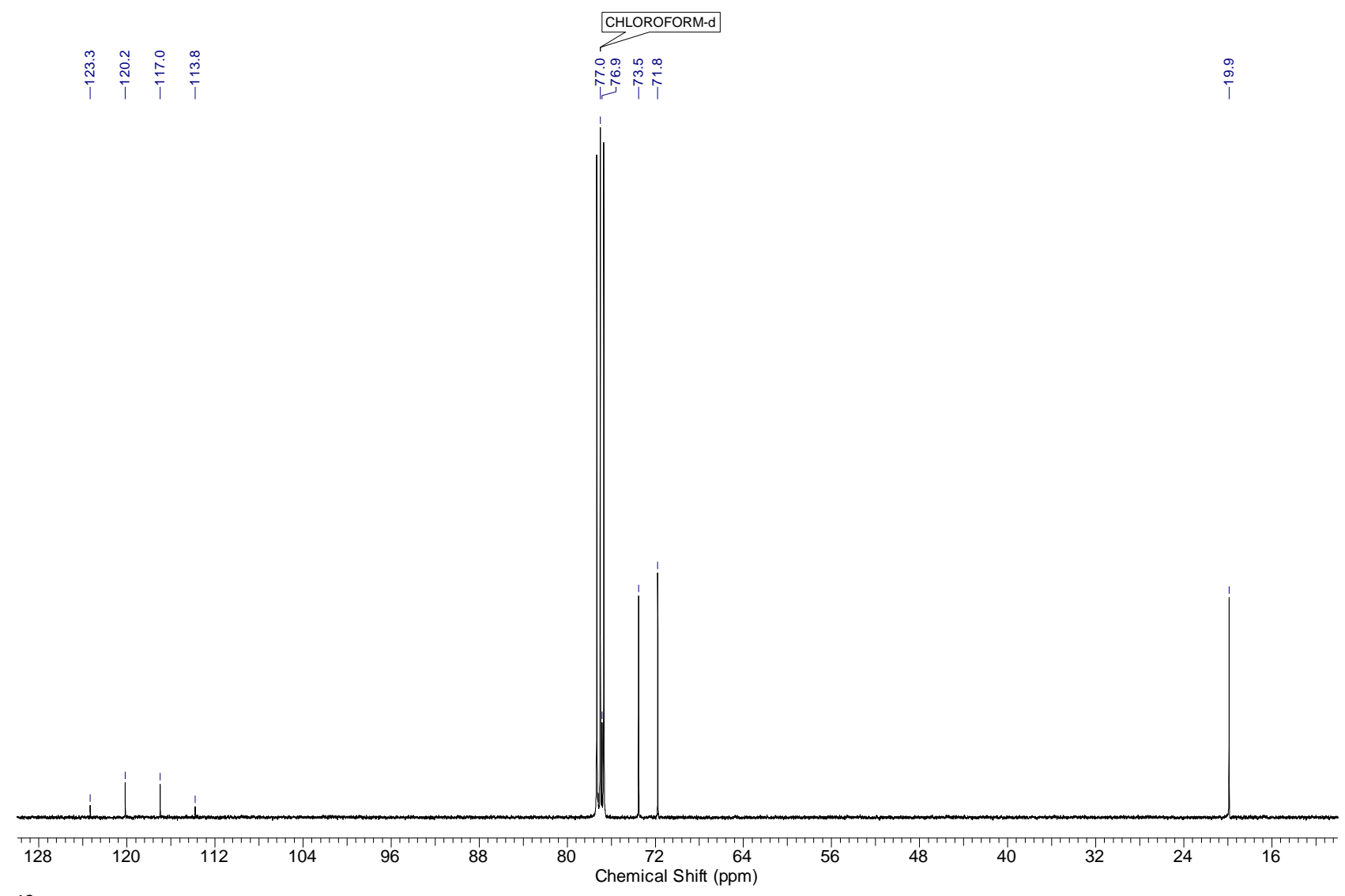

${ }^{13} \mathrm{C} \mathrm{NMR} \mathrm{(100} \mathrm{MHz)} \mathrm{spectrum} \mathrm{of} \mathrm{triflate} 8$ in $\mathrm{CDCl}_{3}(10-130 \mathrm{ppm})$ 


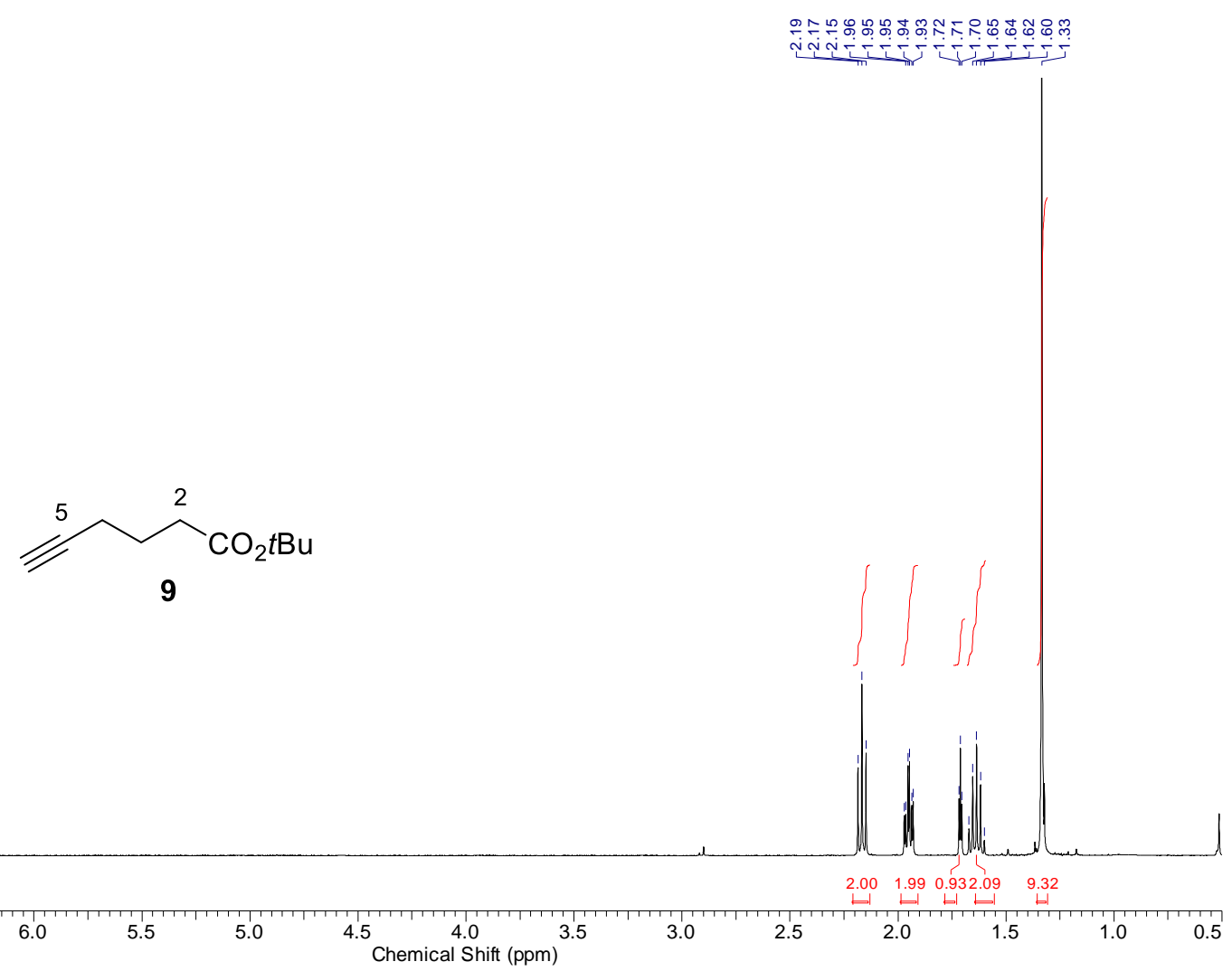

${ }^{1} \mathrm{H}$ NMR $(400 \mathrm{MHz})$ spectrum of hexynoate 9 in $\mathrm{C}_{6} \mathrm{D}_{6}(0.5-7.5 \mathrm{ppm})$

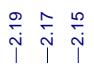

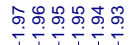

츄유
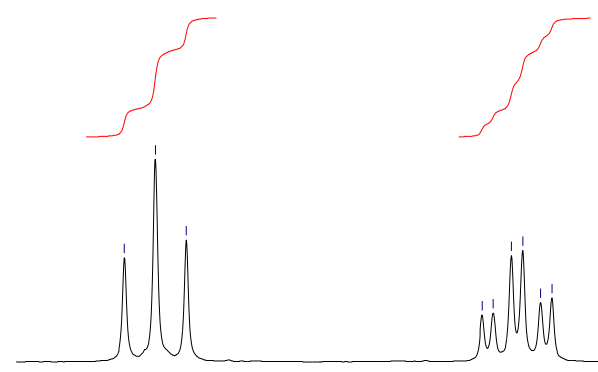

NMR (400

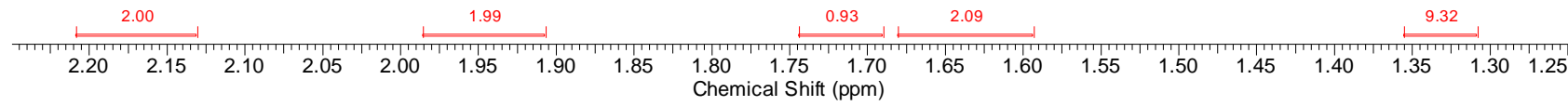

${ }^{1} \mathrm{H}$ NMR (400 MHz) spectrum of hexynoate 9 in $\mathrm{C}_{6} \mathrm{D}_{6}(1.25-2.25 \mathrm{ppm})$ 


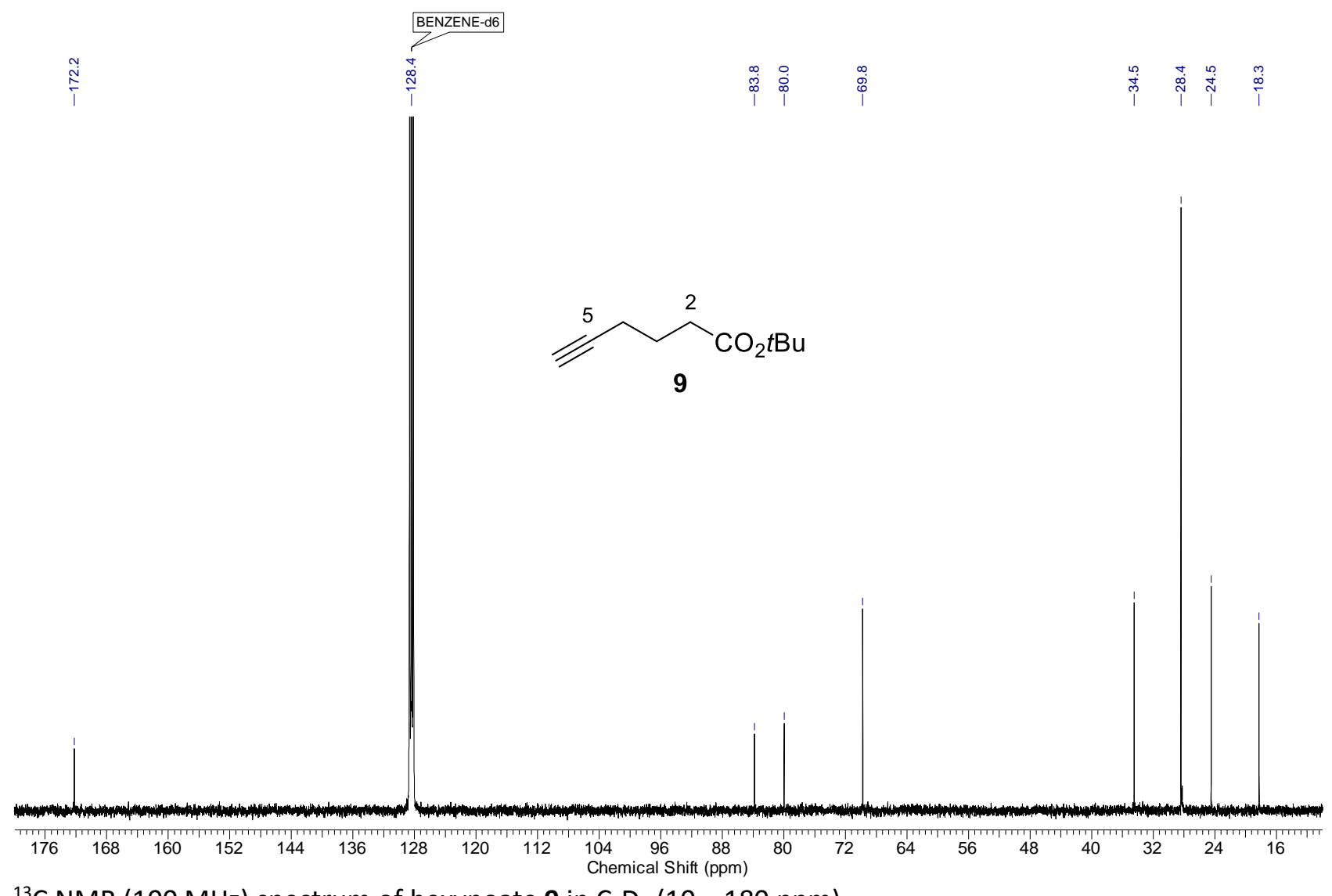

${ }^{13} \mathrm{C}$ NMR $(100 \mathrm{MHz})$ spectrum of hexynoate 9 in $\mathrm{C}_{6} \mathrm{D}_{6}(10-180 \mathrm{ppm})$ 


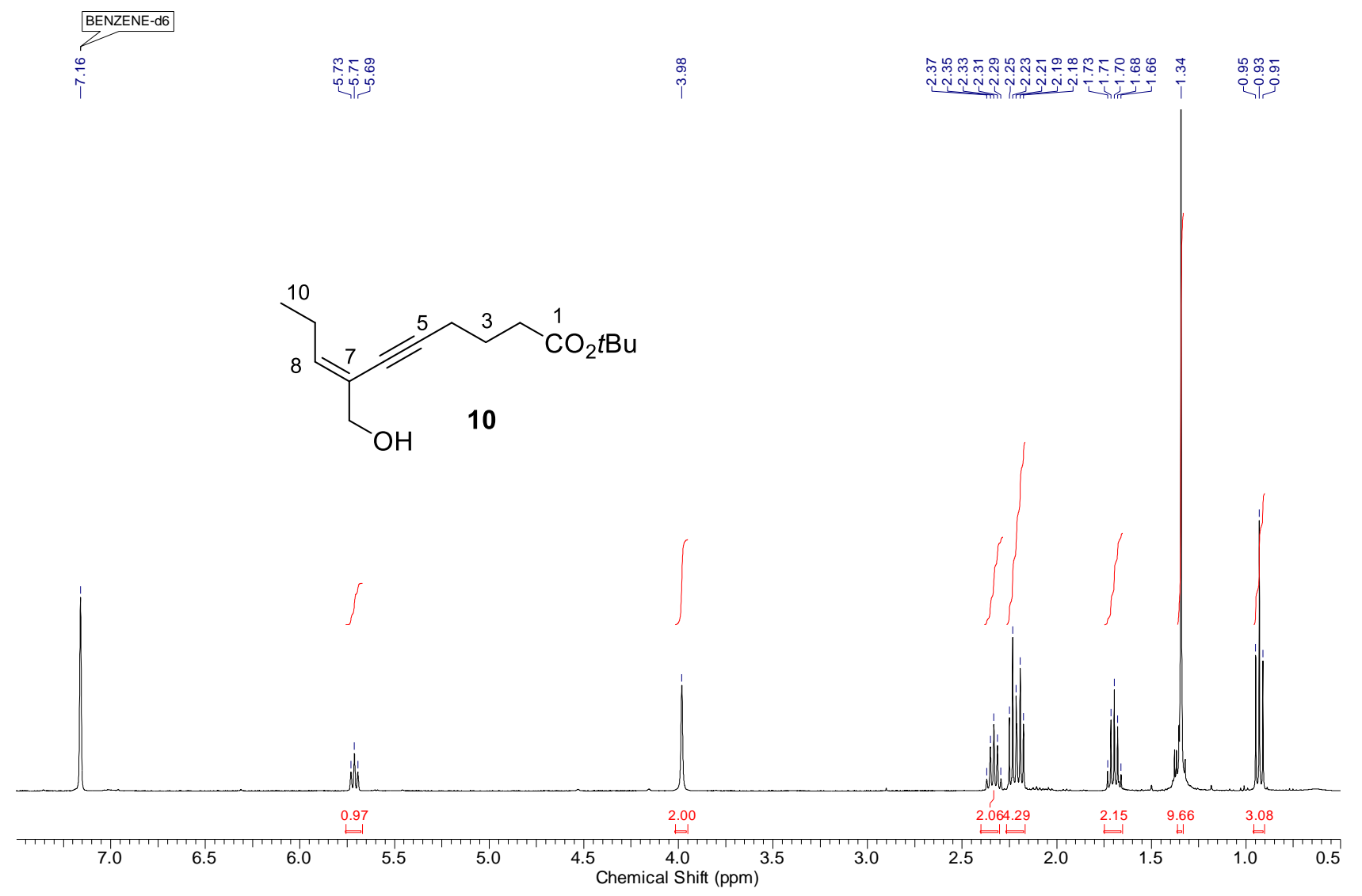

${ }^{1} \mathrm{H}$ NMR (400 MHz) spectrum of enynol 10 in $C_{6} D_{6}(0.5-7.5 \mathrm{ppm})$

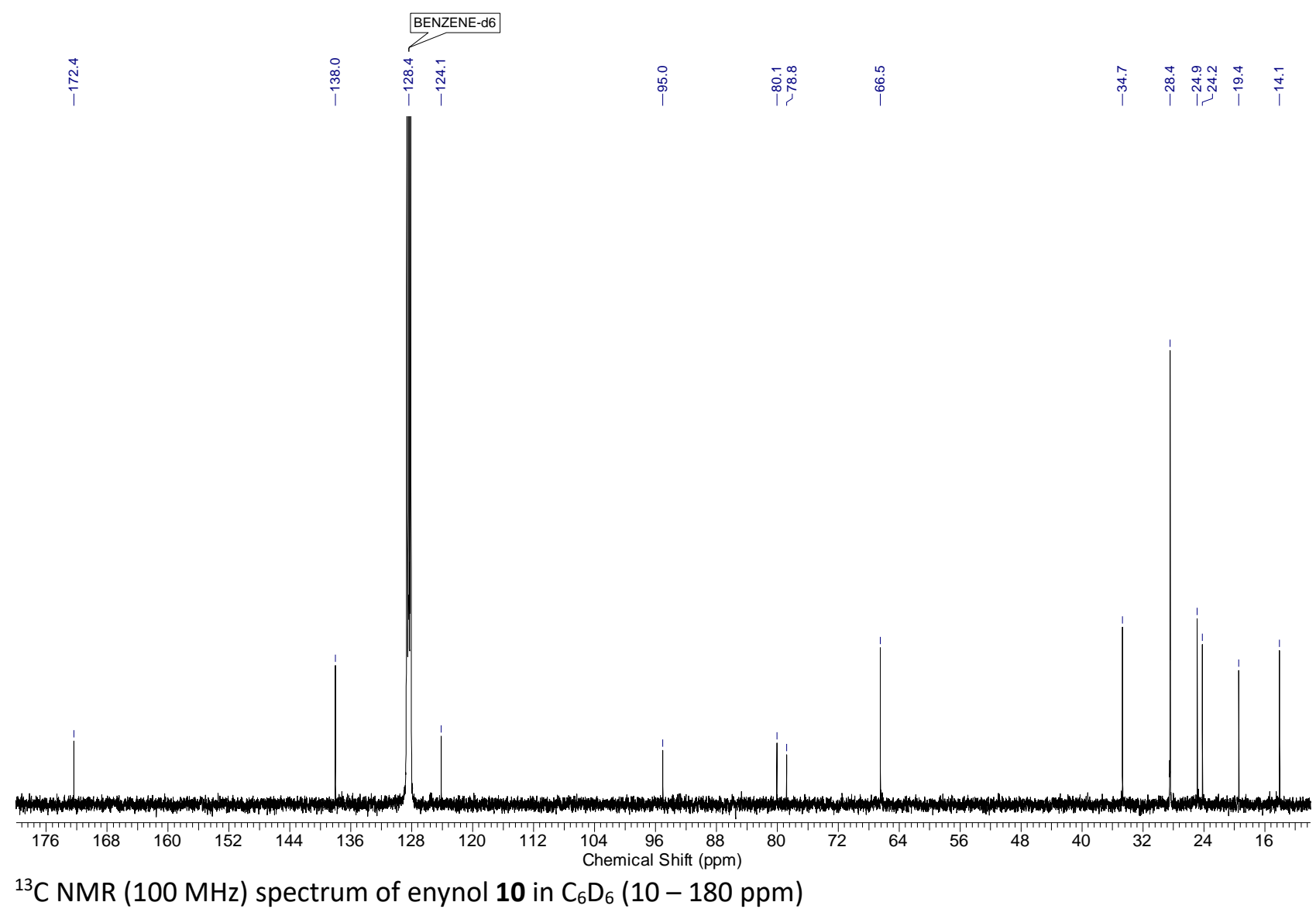




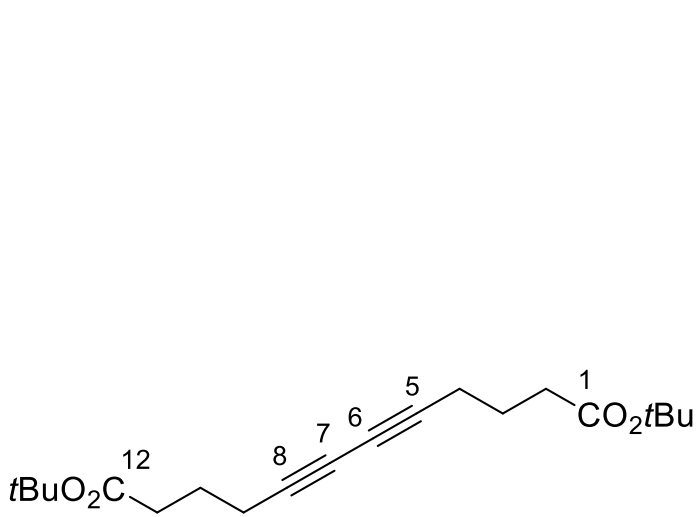

di-tert-butyl dodeca-5,7-diynedioate

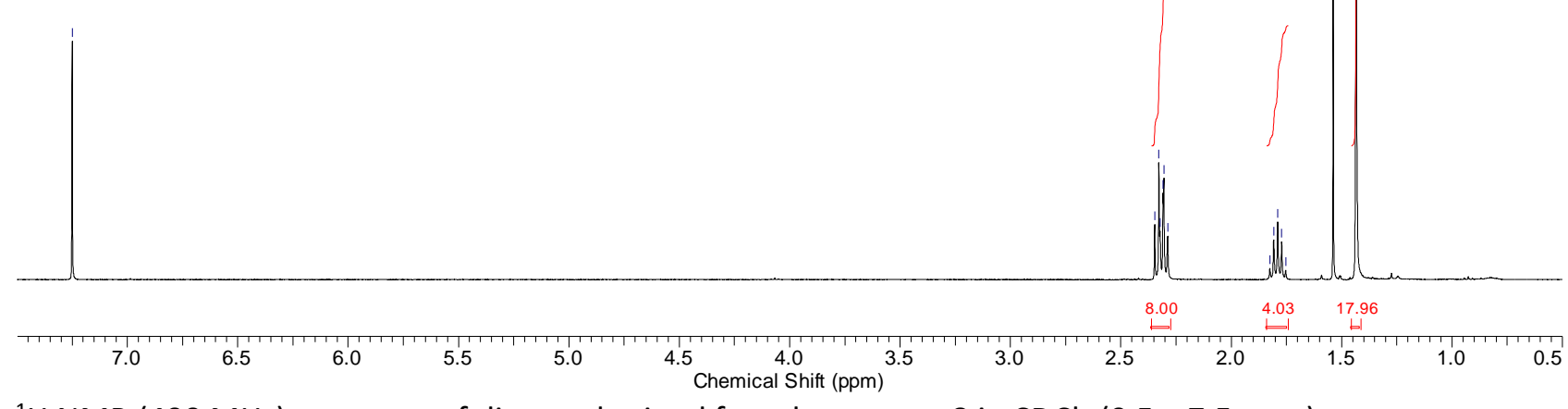

${ }^{1} \mathrm{H} \mathrm{NMR}(400 \mathrm{MHz})$ spectrum of dimer, obtained from hexynoate 9 in $\mathrm{CDCl}_{3}(0.5-7.5 \mathrm{ppm})$

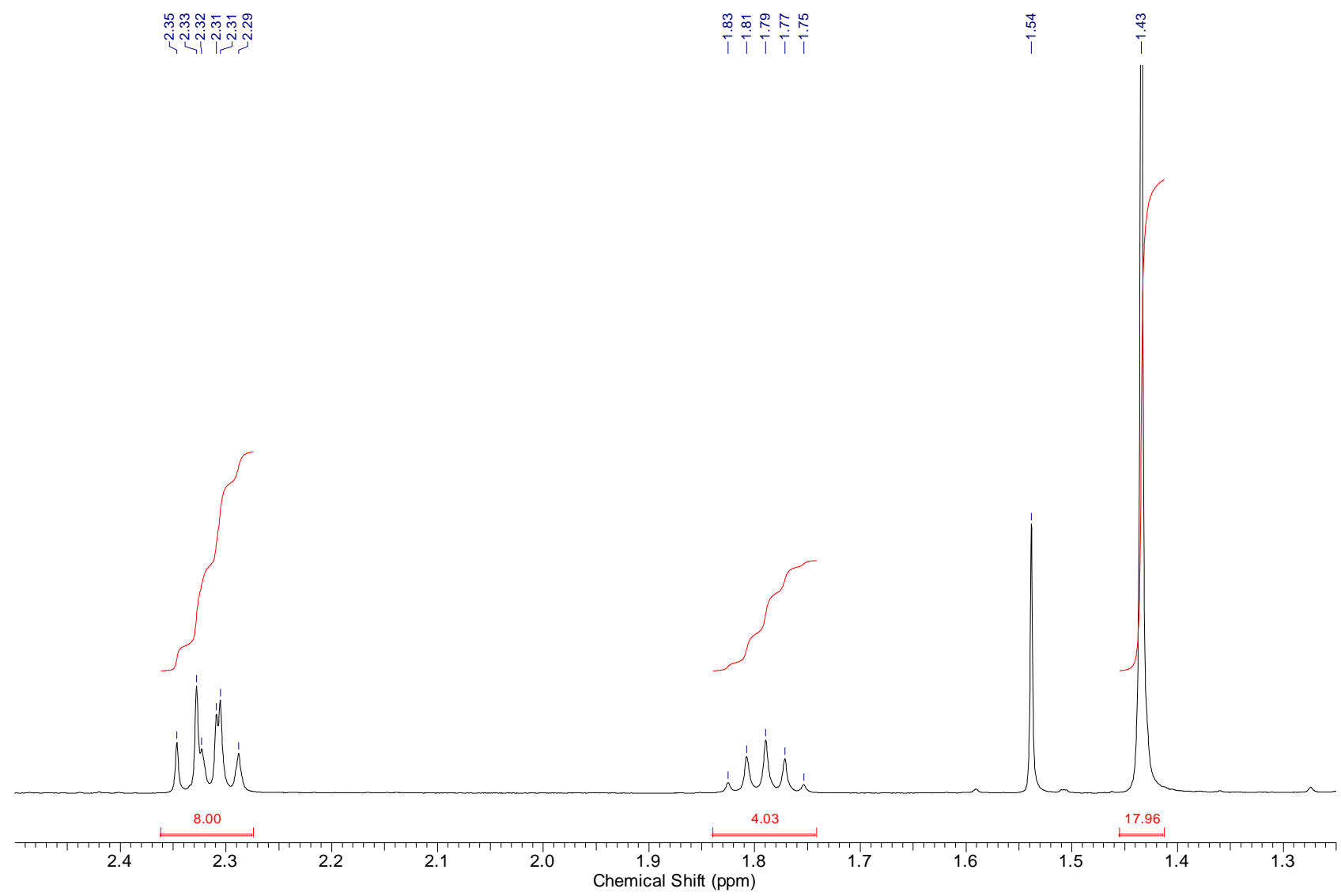

${ }^{1} \mathrm{H} \mathrm{NMR}(400 \mathrm{MHz})$ spectrum of dimer, obtained from hexynoate 9 in $\mathrm{CDCl}_{3}(1.25-2.5 \mathrm{ppm})$ 


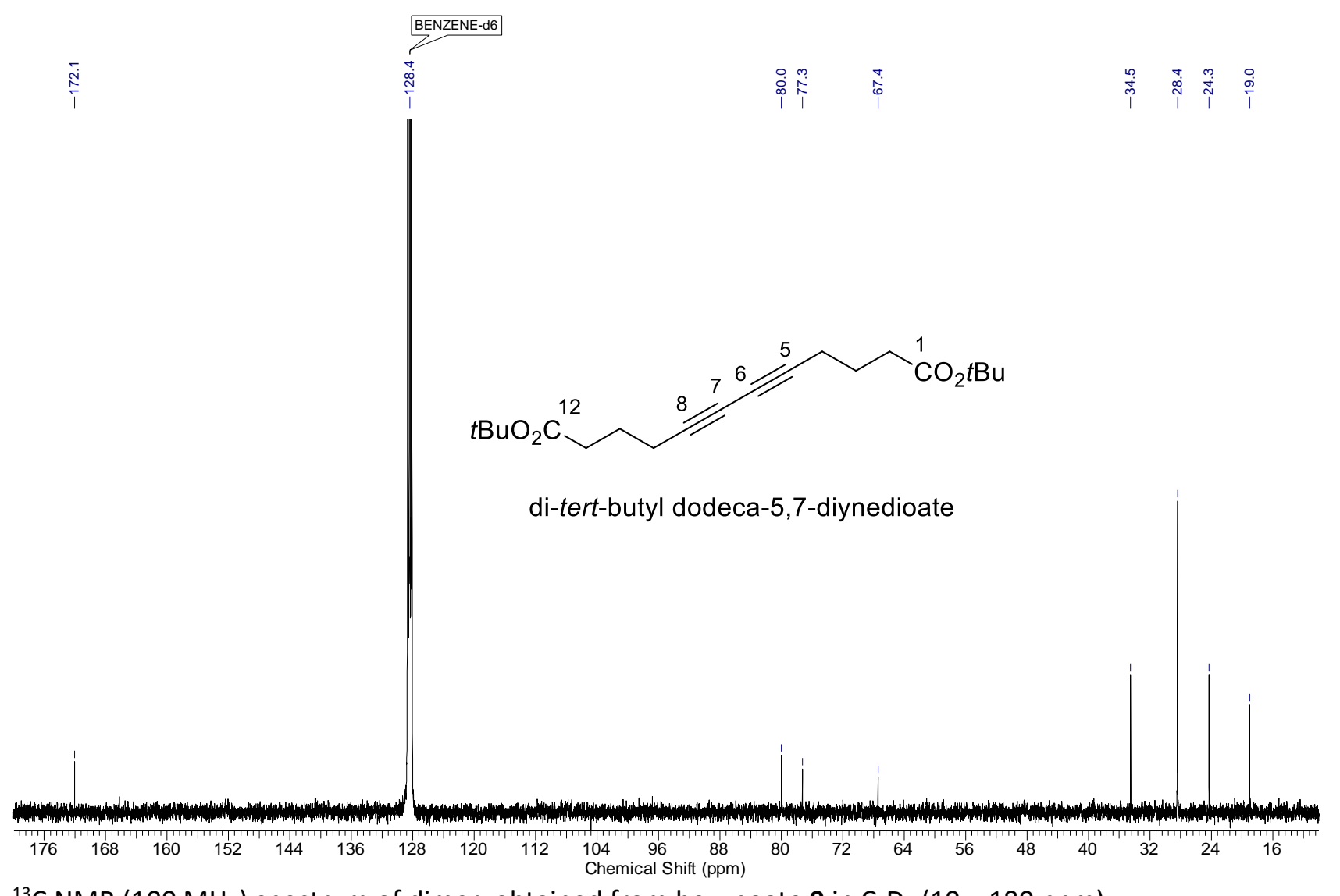

${ }^{13} \mathrm{C}$ NMR $(100 \mathrm{MHz})$ spectrum of dimer, obtained from hexynoate 9 in $\mathrm{C}_{6} \mathrm{D}_{6}(10-180 \mathrm{ppm})$ 


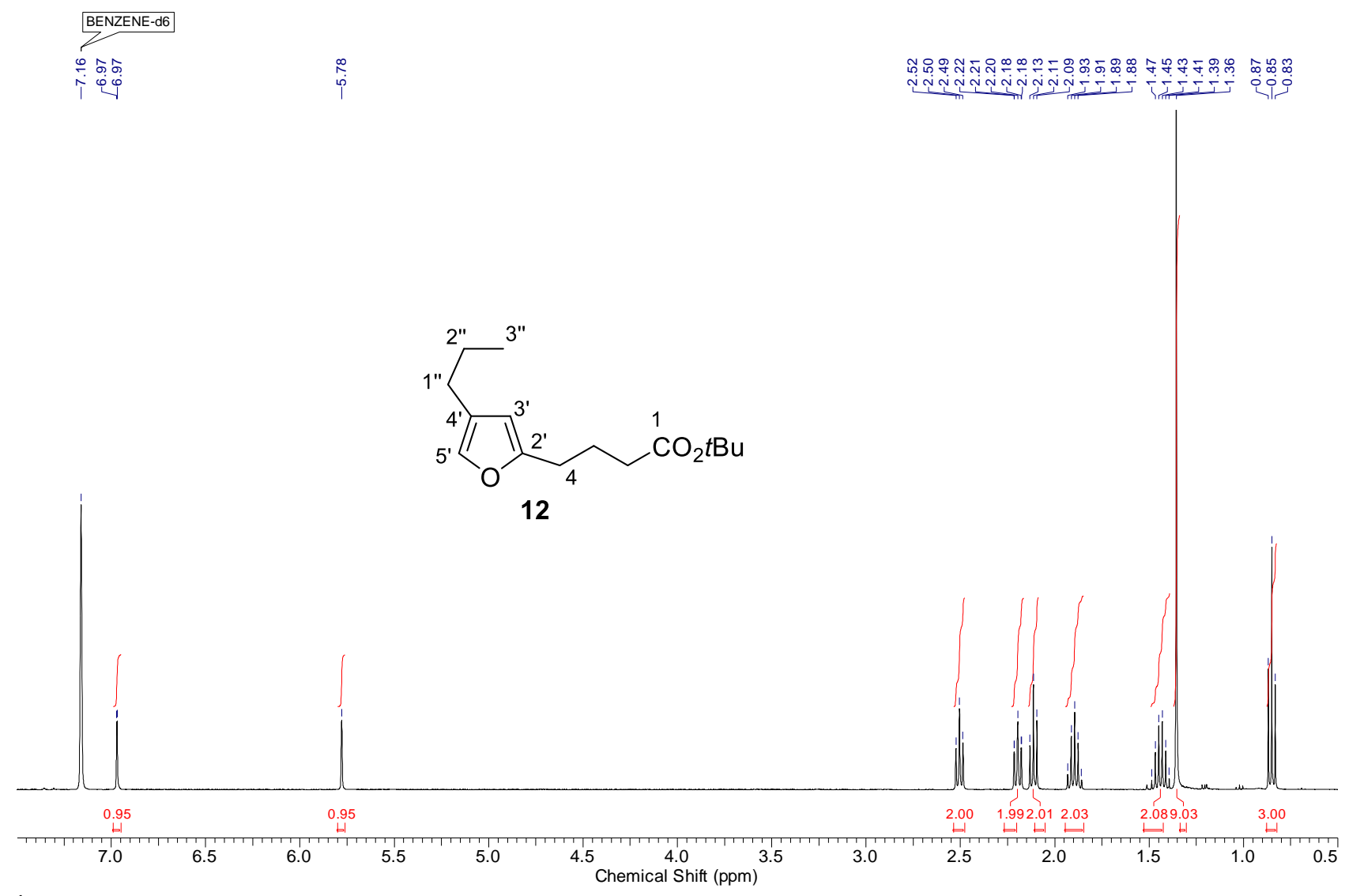

${ }^{1} \mathrm{H}$ NMR (400 MHz) spectrum of furanylbutanoate 12 in $\mathrm{C}_{6} \mathrm{D}_{6}(0.5-7.5 \mathrm{ppm})$

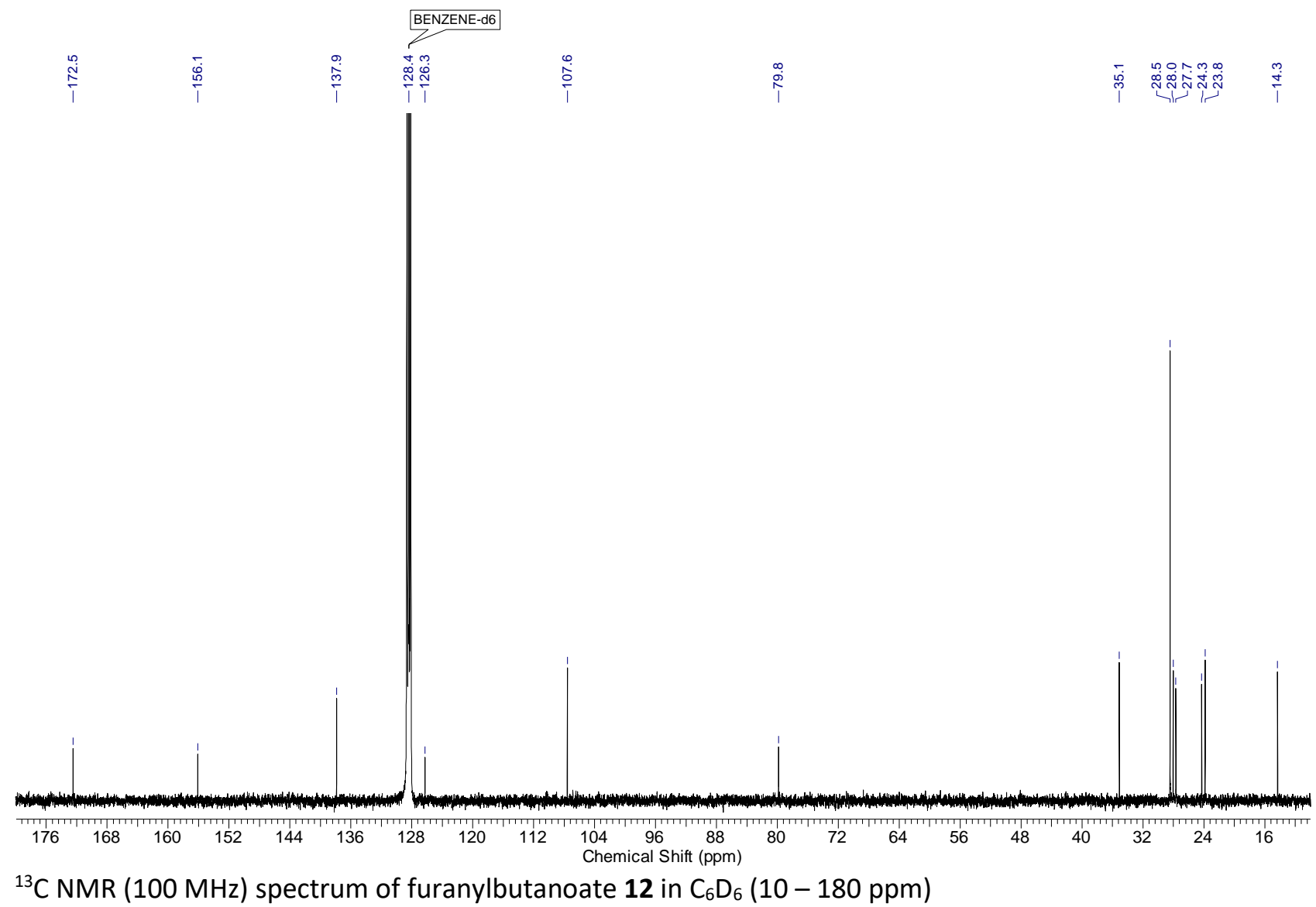




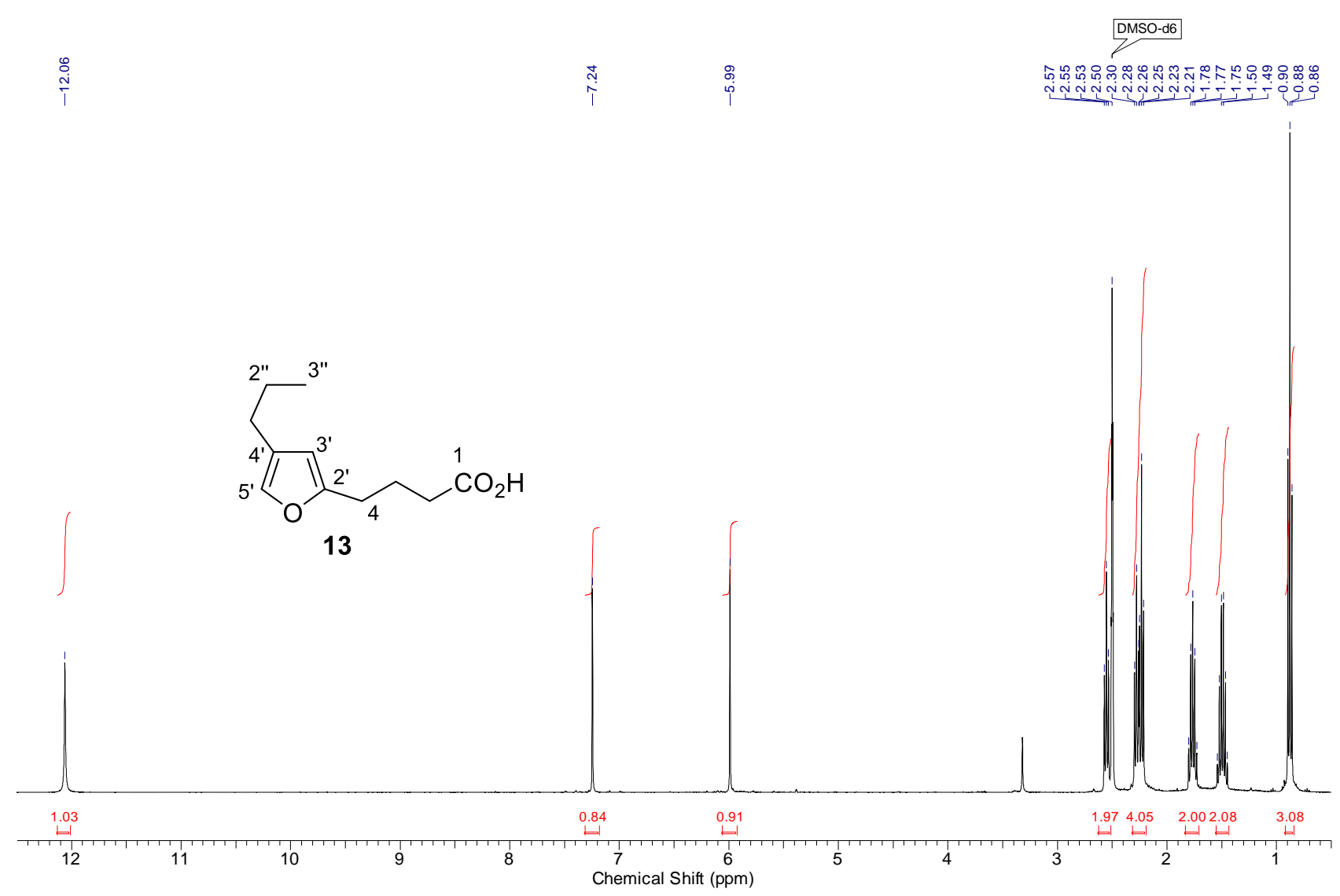

${ }^{1} \mathrm{H}$ NMR $(400 \mathrm{MHz})$ spectrum of furylbutanoic acid 13 in DMSO-d 6 (0.5-12.5 ppm)

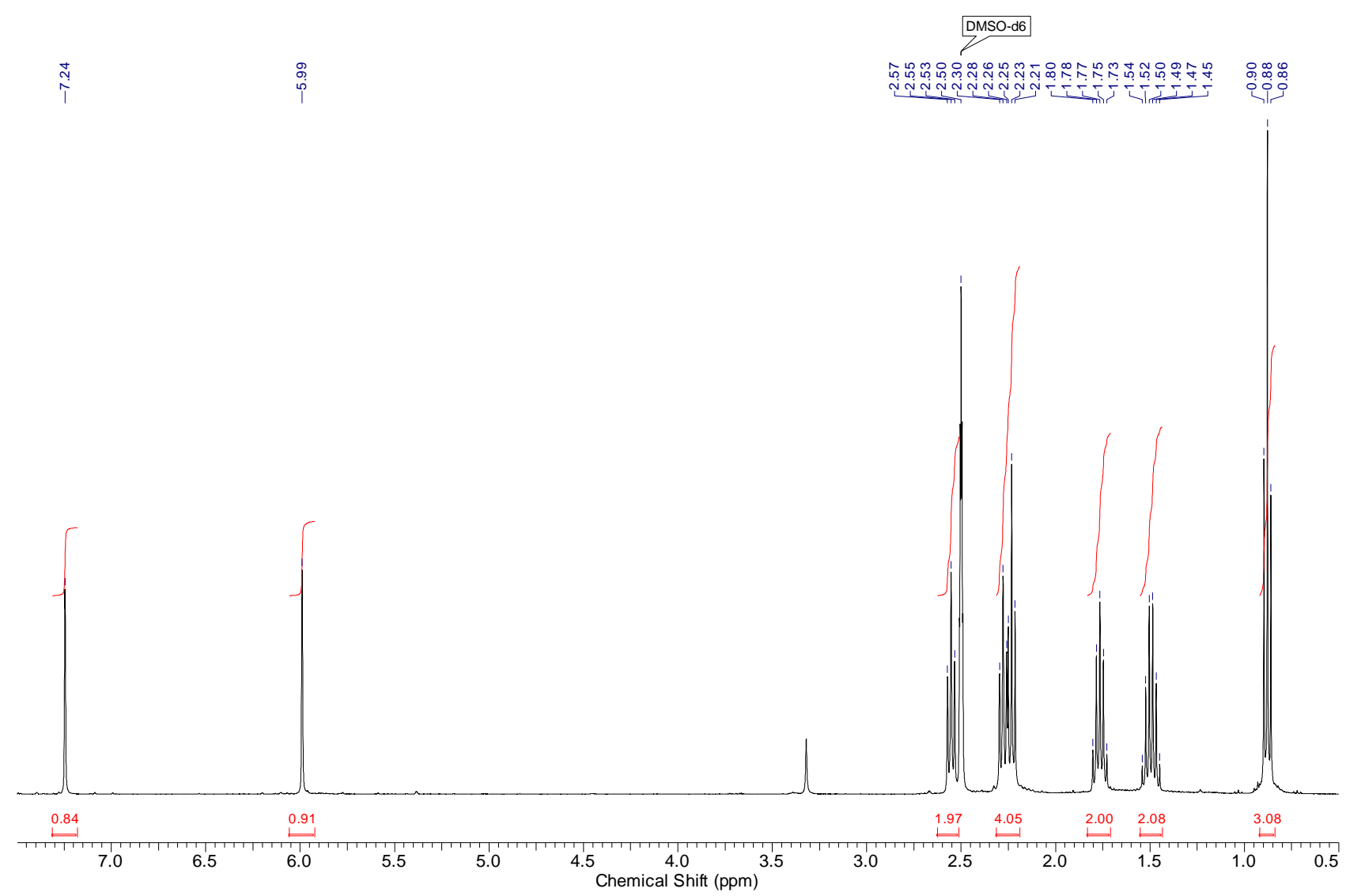

${ }^{1} \mathrm{H} \mathrm{NMR}(400 \mathrm{MHz})$ spectrum of furylbutanoic acid 13 in DMSO-d 6 (0.5- $\left.7.5 \mathrm{ppm}\right)$ 


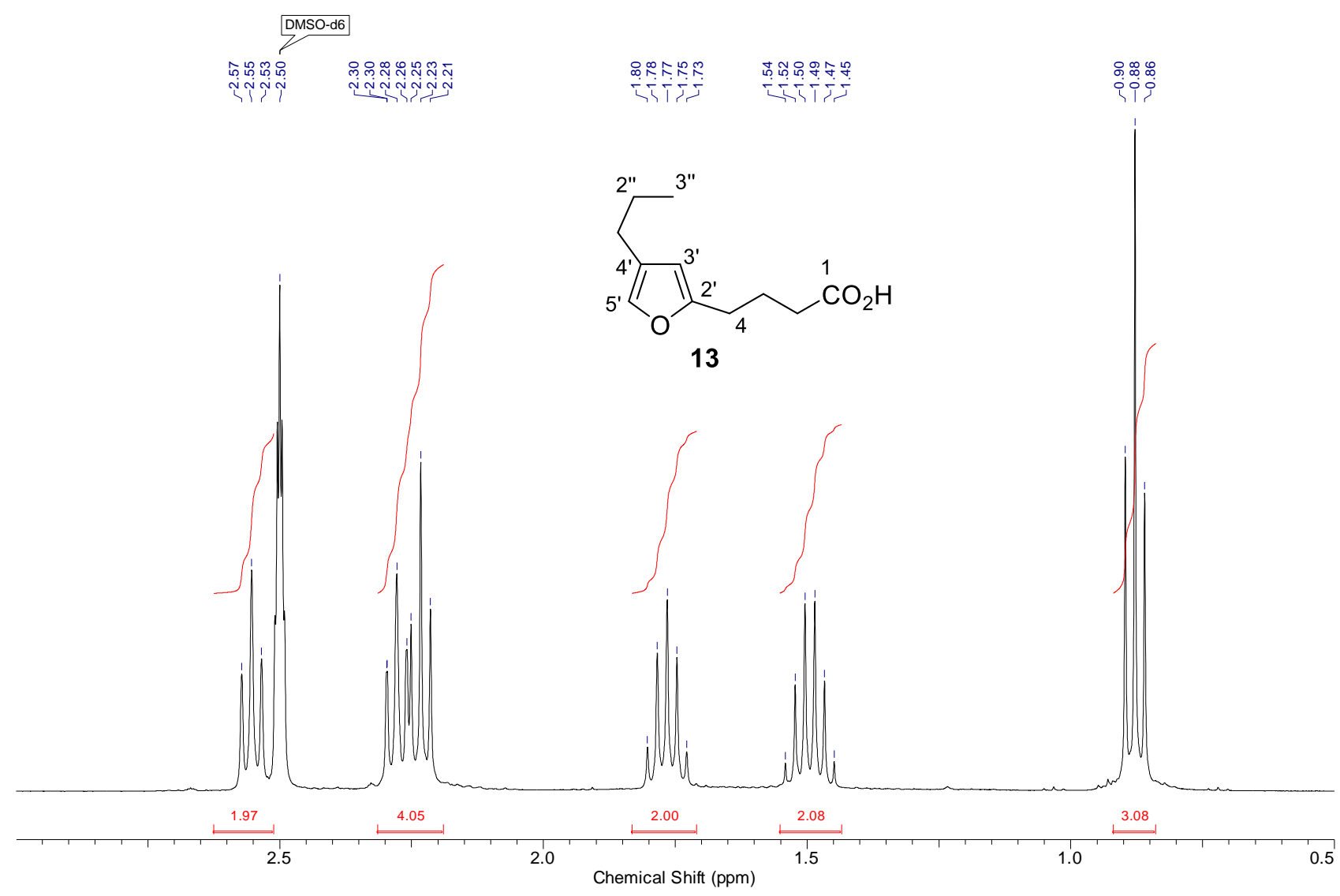

${ }^{1} \mathrm{H} \mathrm{NMR}(400 \mathrm{MHz})$ spectrum of furylbutanoic acid 13 in DMSO-d 6 (0.5-3.0 ppm)

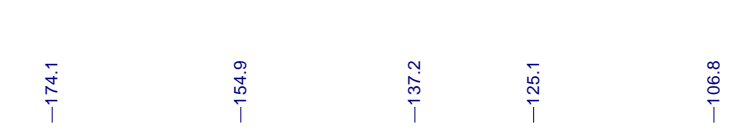

DMSO-d6

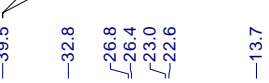

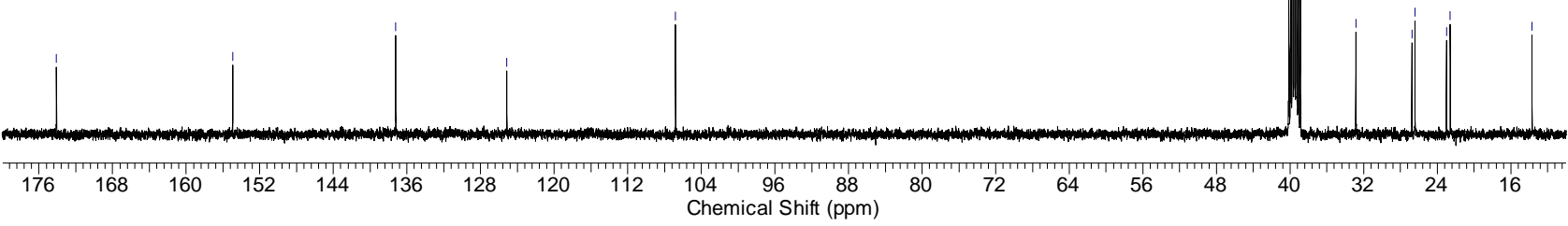

${ }^{13} \mathrm{C}$ NMR (100 MHz) spectrum of furylbutanoic acid 13 in DMSO-d 6 (10 - $180 \mathrm{ppm}$ ) 


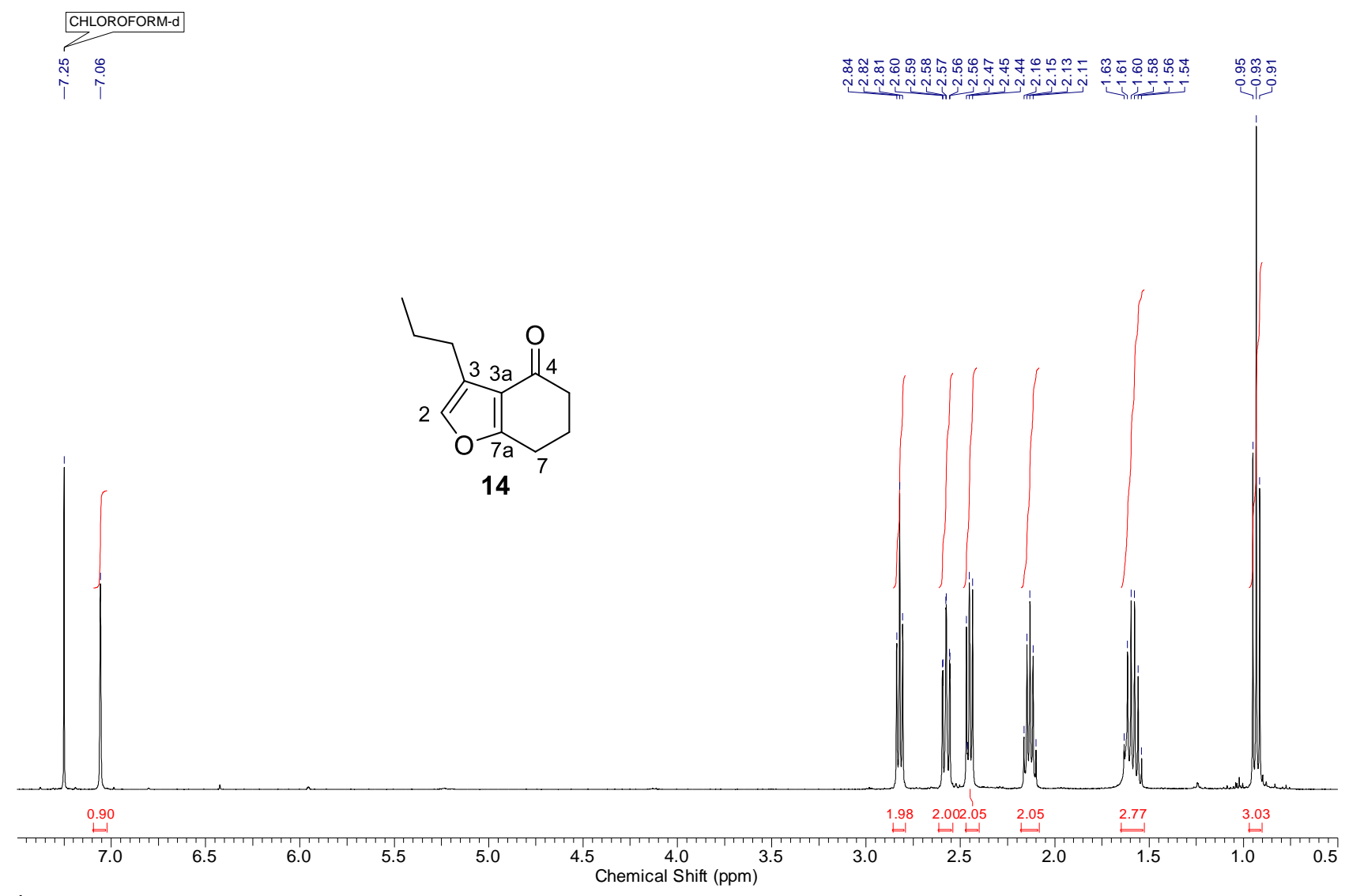

${ }^{1} \mathrm{H} \mathrm{NMR}(400 \mathrm{MHz})$ spectrum of dihydrobenzofuranone 14 in $\mathrm{CDCl}_{3}(0.5-7.5 \mathrm{ppm})$

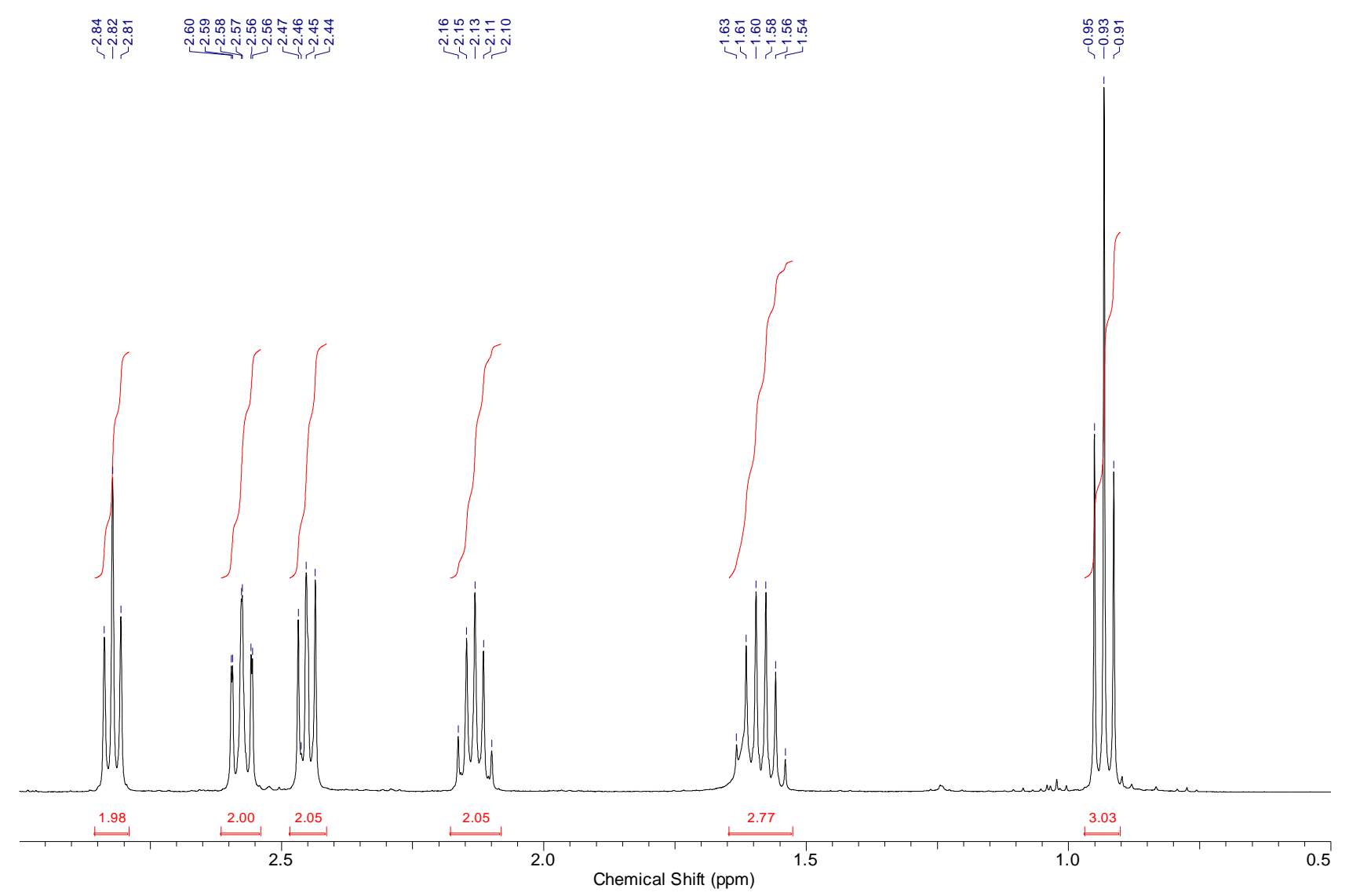

${ }^{1} \mathrm{H} \mathrm{NMR}(400 \mathrm{MHz})$ spectrum of dihydrobenzofuranone 14 in $\mathrm{CDCl}_{3}(0.5-3.0 \mathrm{ppm})$ 


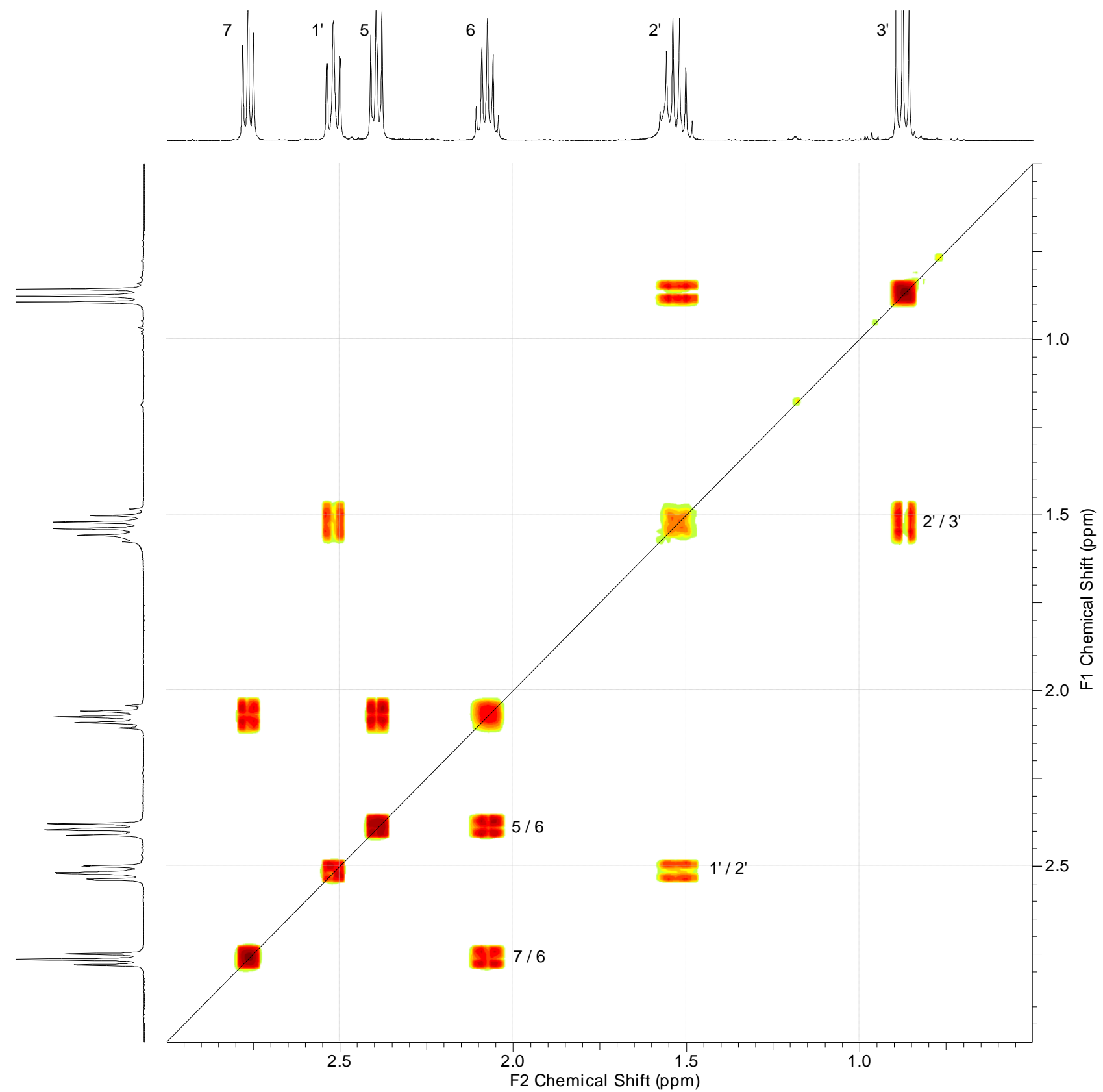

COSY spectrum of dihydrobenzofuranone 14 in $\mathrm{CDCl}_{3}(0.5-3.0 \mathrm{ppm})$

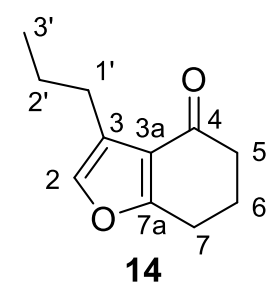




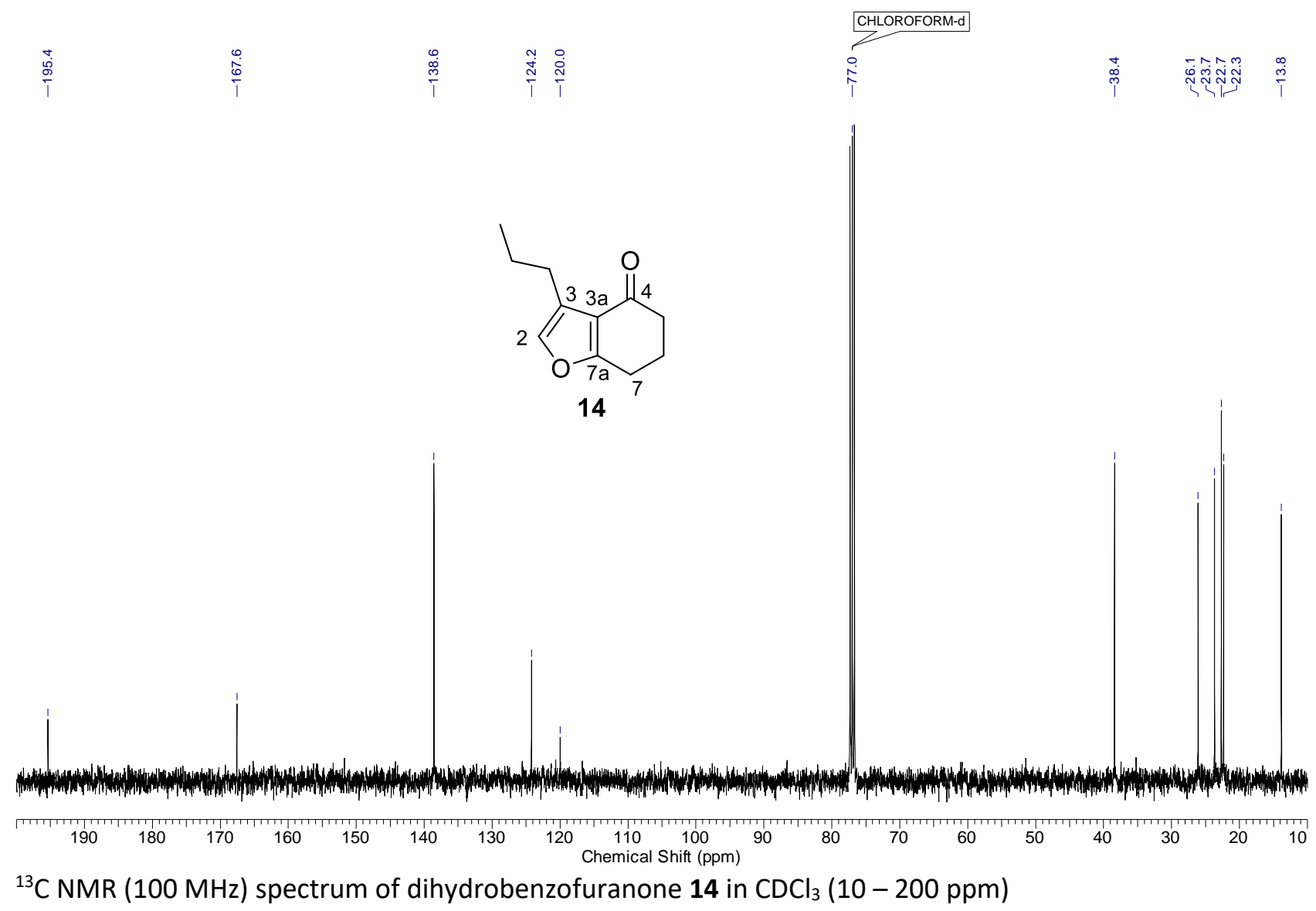




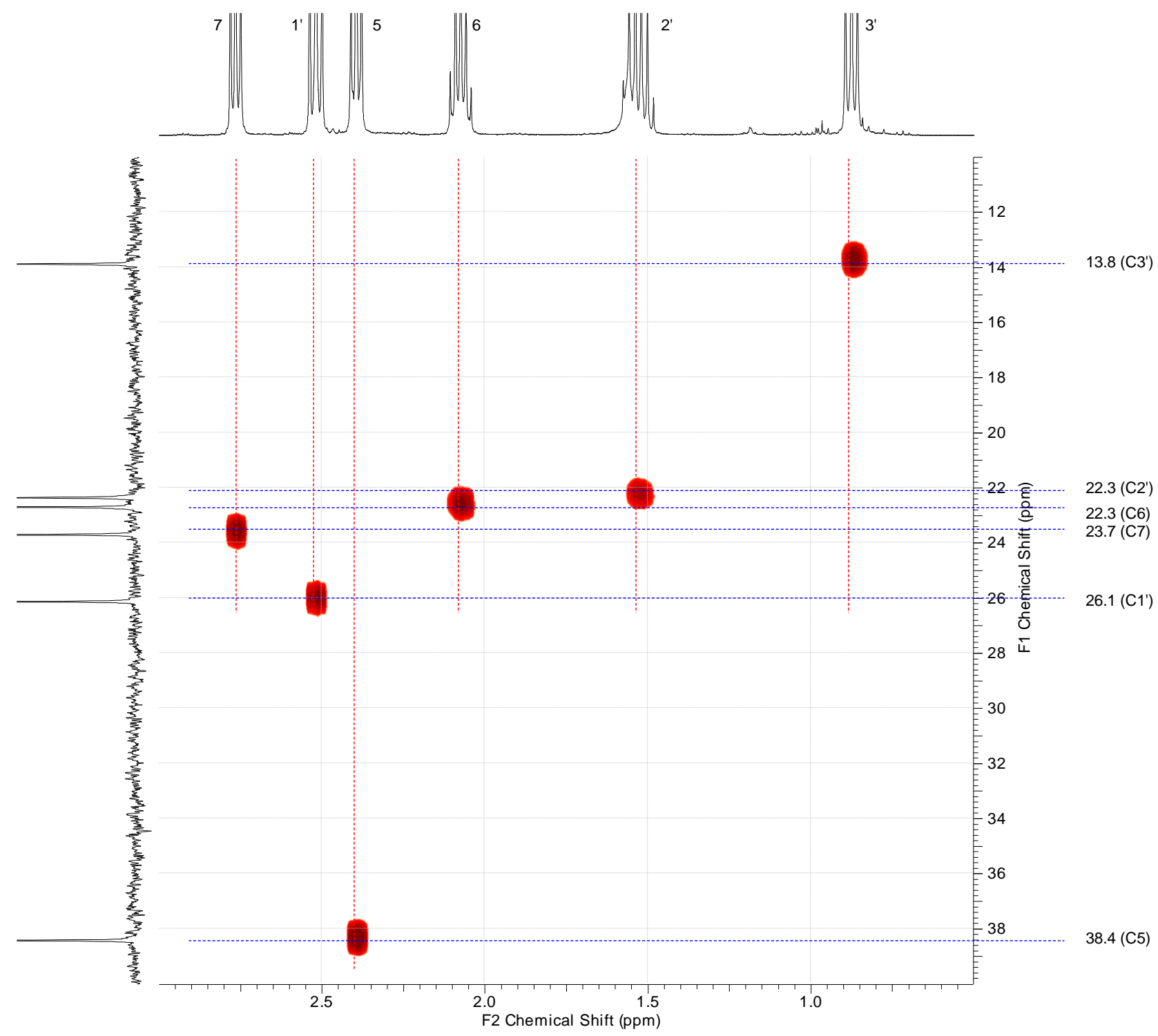

$\mathrm{HSQC}$ spectrum of dihydrobenzofuranone 14 in $\mathrm{CDCl}_{3}(0.3-3.0,10-40 \mathrm{ppm})$

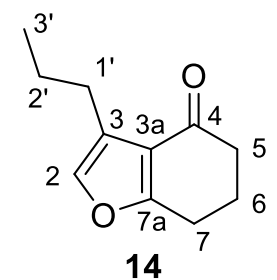




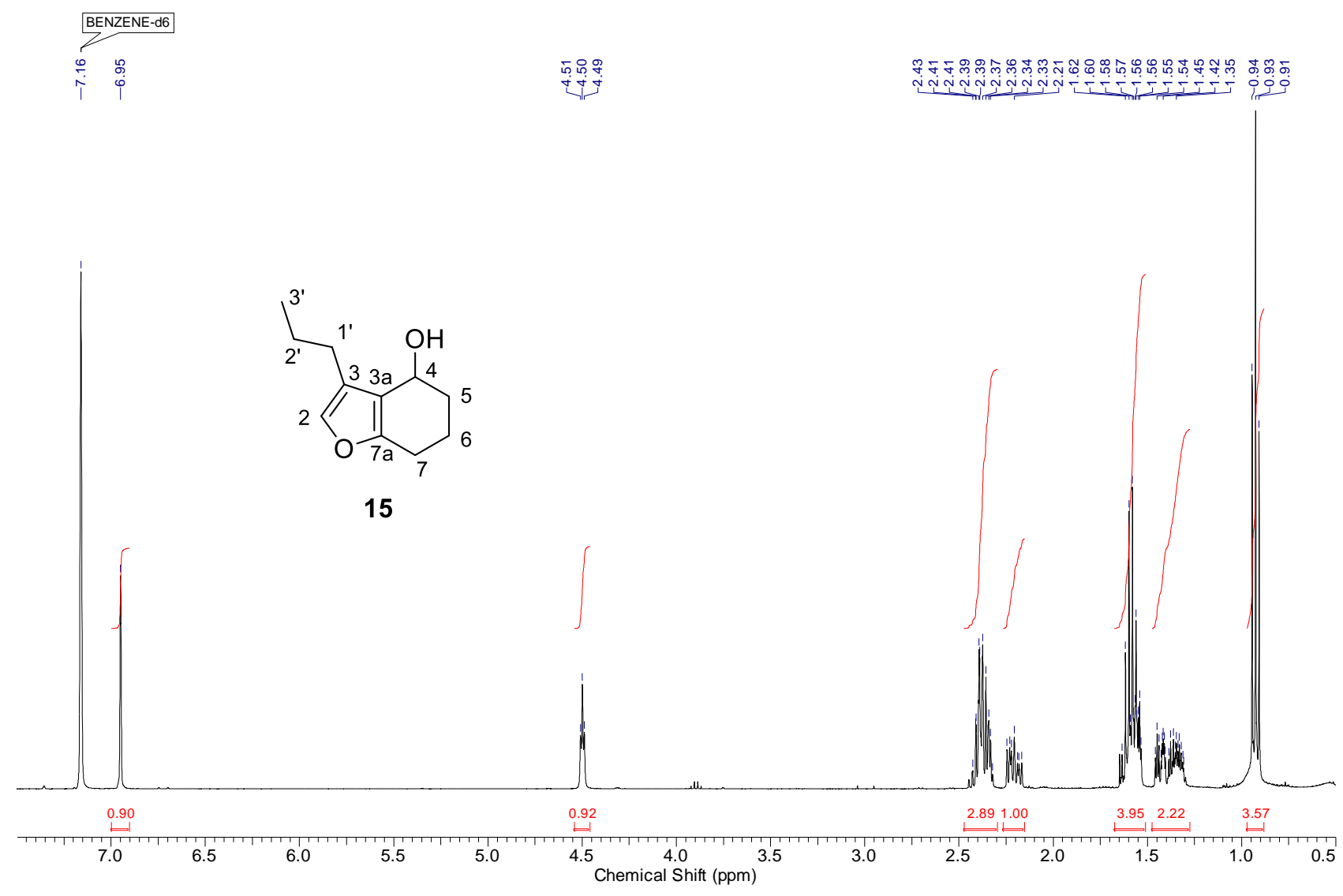

${ }^{1} \mathrm{H}$ NMR $(400 \mathrm{MHz})$ spectrum of tetrahydrobenzofuranol 15 in $\mathrm{C}_{6} \mathrm{D}_{6}(0.5-7.5 \mathrm{ppm})$

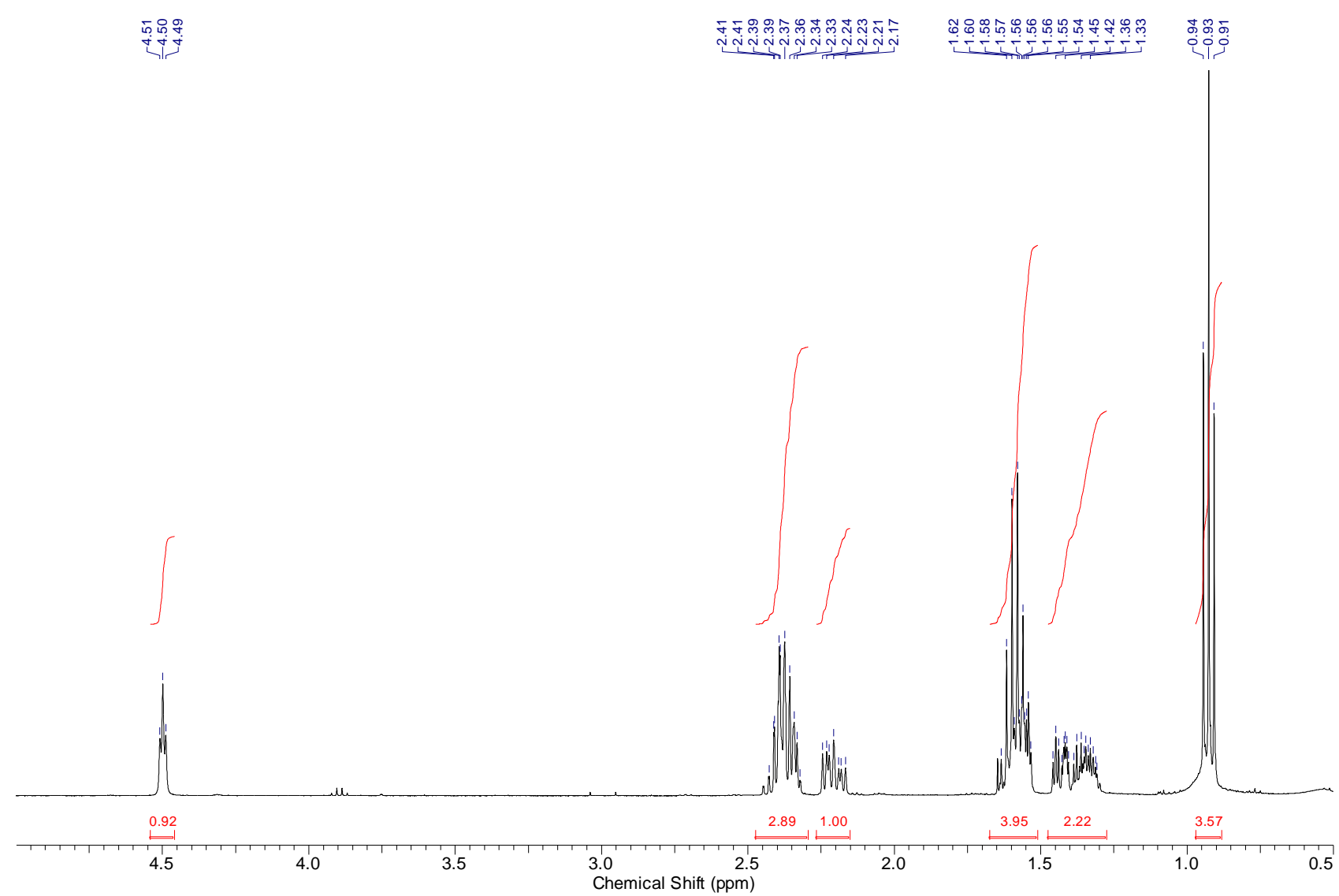

${ }^{1} \mathrm{H} \mathrm{NMR}(400 \mathrm{MHz})$ spectrum of tetrahydrobenzofuranol 15 in $\mathrm{C}_{6} \mathrm{D}_{6}(0.5-5.0 \mathrm{ppm})$ 


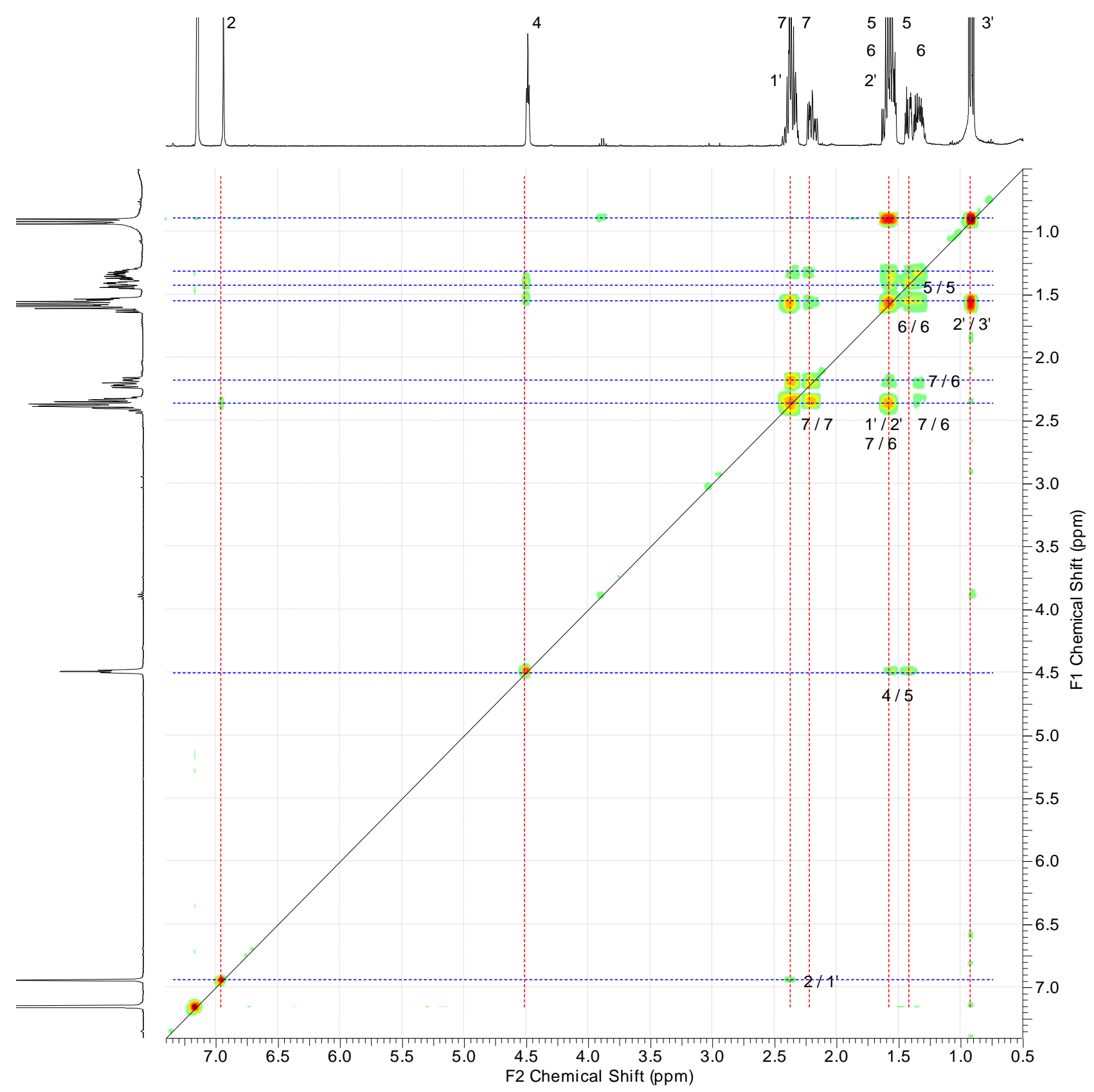

$\operatorname{COSY}(400 \mathrm{MHz})$ spectrum of tetrahydrobenzofuranol 15 in $\mathrm{C}_{6} \mathrm{D}_{6}(0.5-7.5 \mathrm{ppm})$

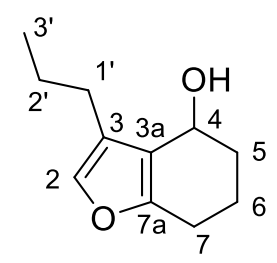

15 


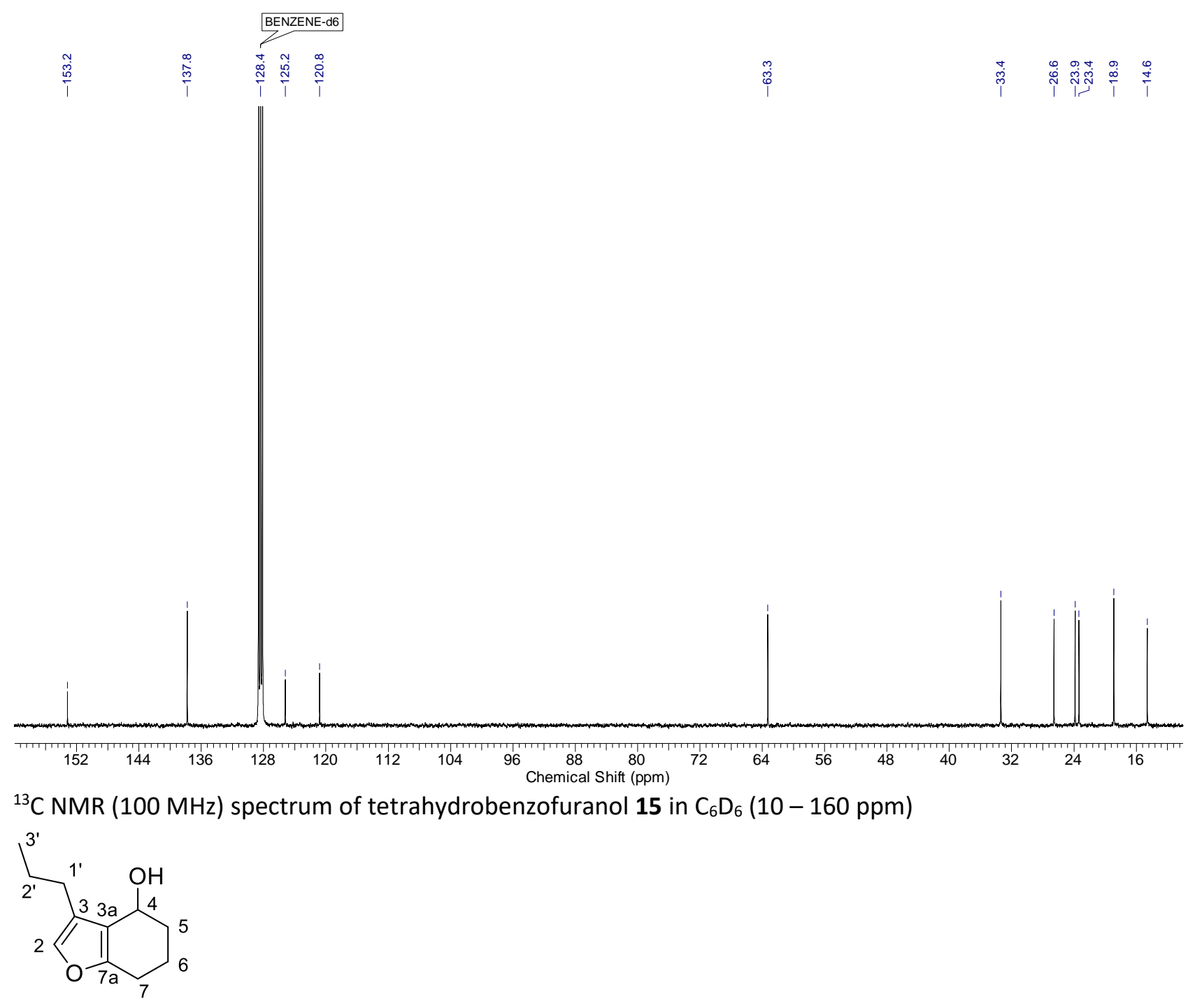

15 


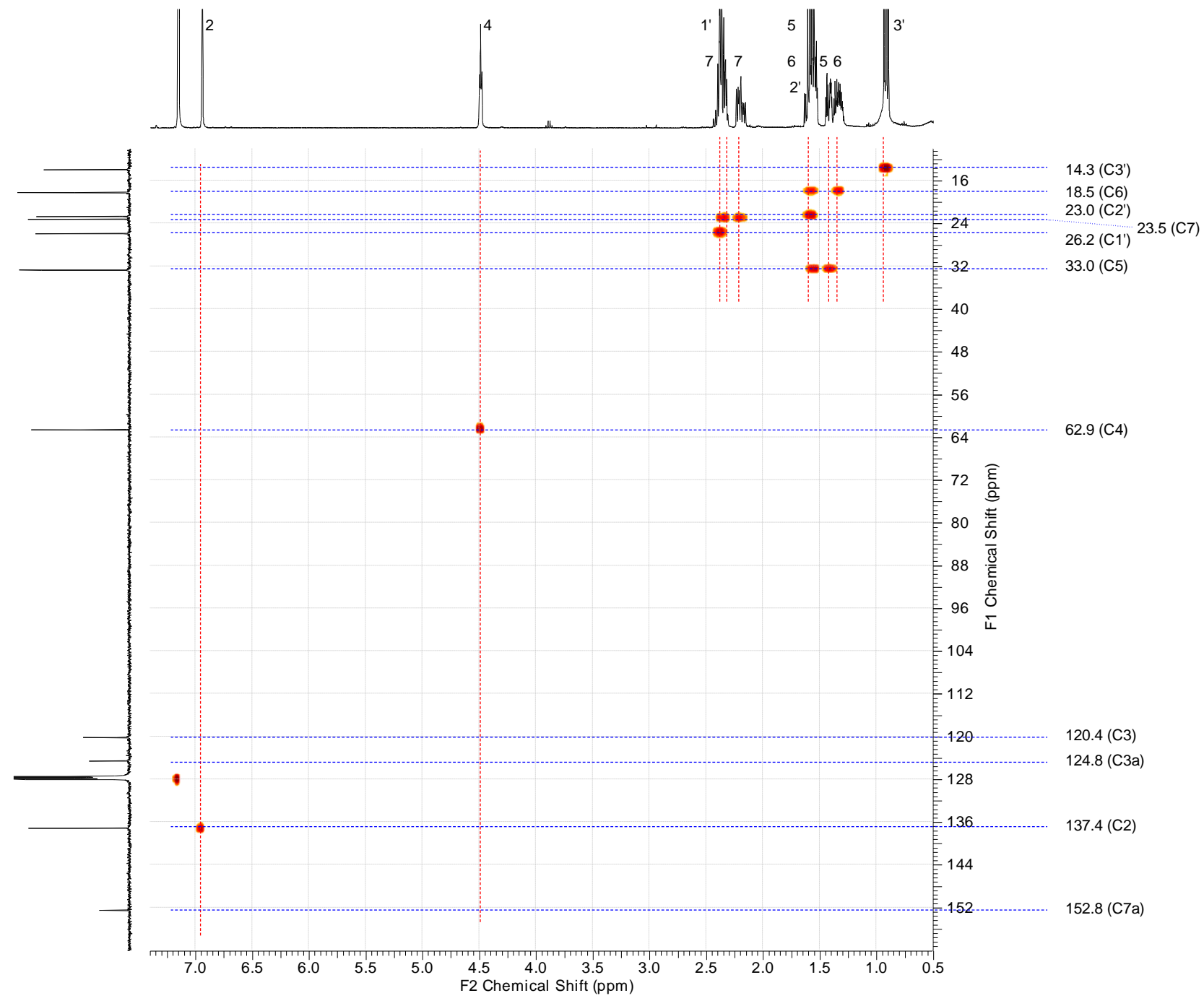

HSQC spectrum of tetrahydrobenzofuranol 15 in $\mathrm{C}_{6} \mathrm{D}_{6}(0.5-7.4,10-160 \mathrm{ppm})$

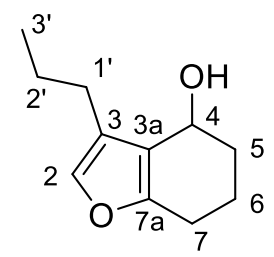

15 


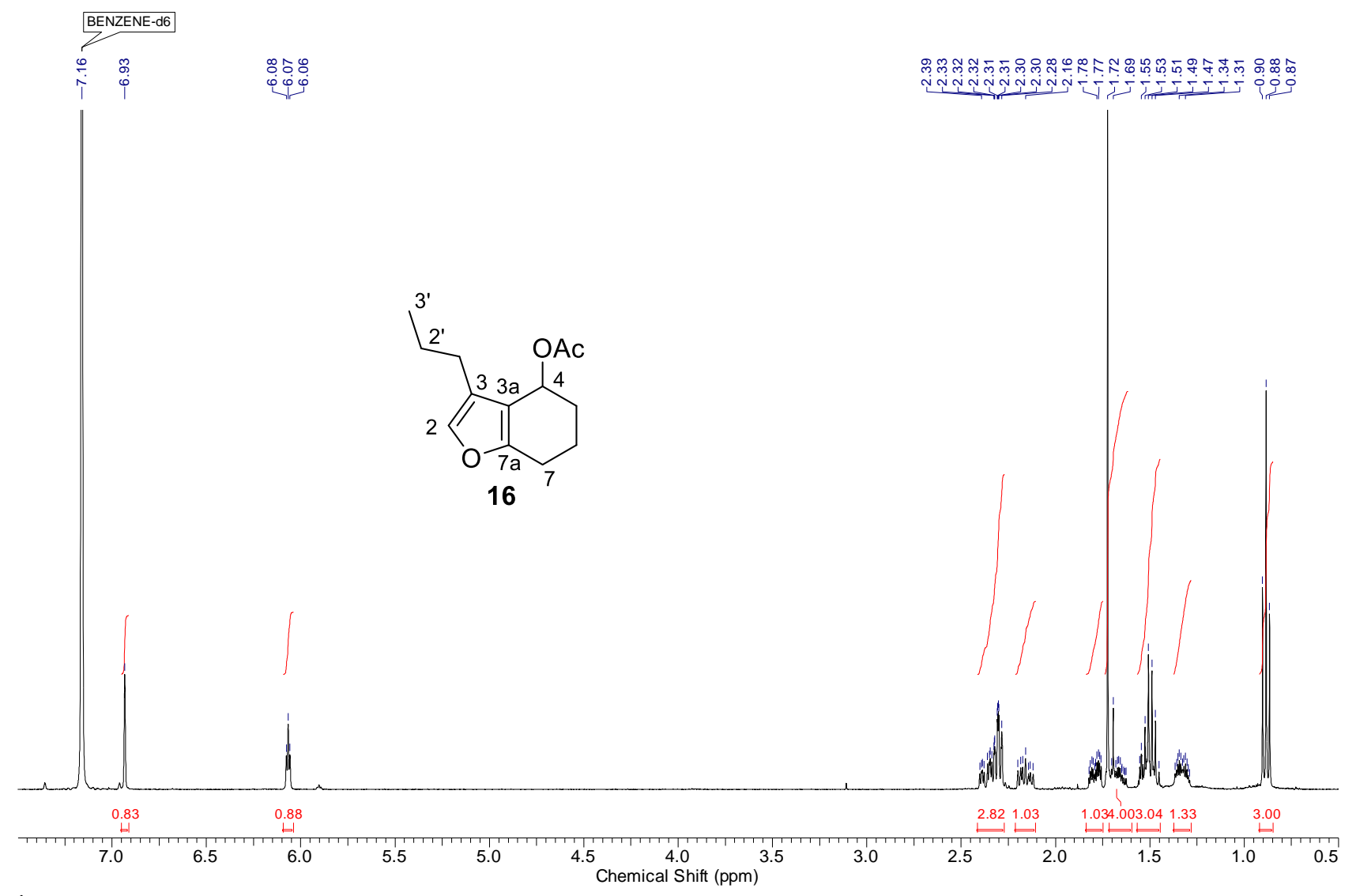

${ }^{1} \mathrm{H}$ NMR $(400 \mathrm{MHz})$ spectrum of acetate 16 in $\mathrm{C}_{6} \mathrm{D}_{6}(0.5-7.5 \mathrm{ppm})$

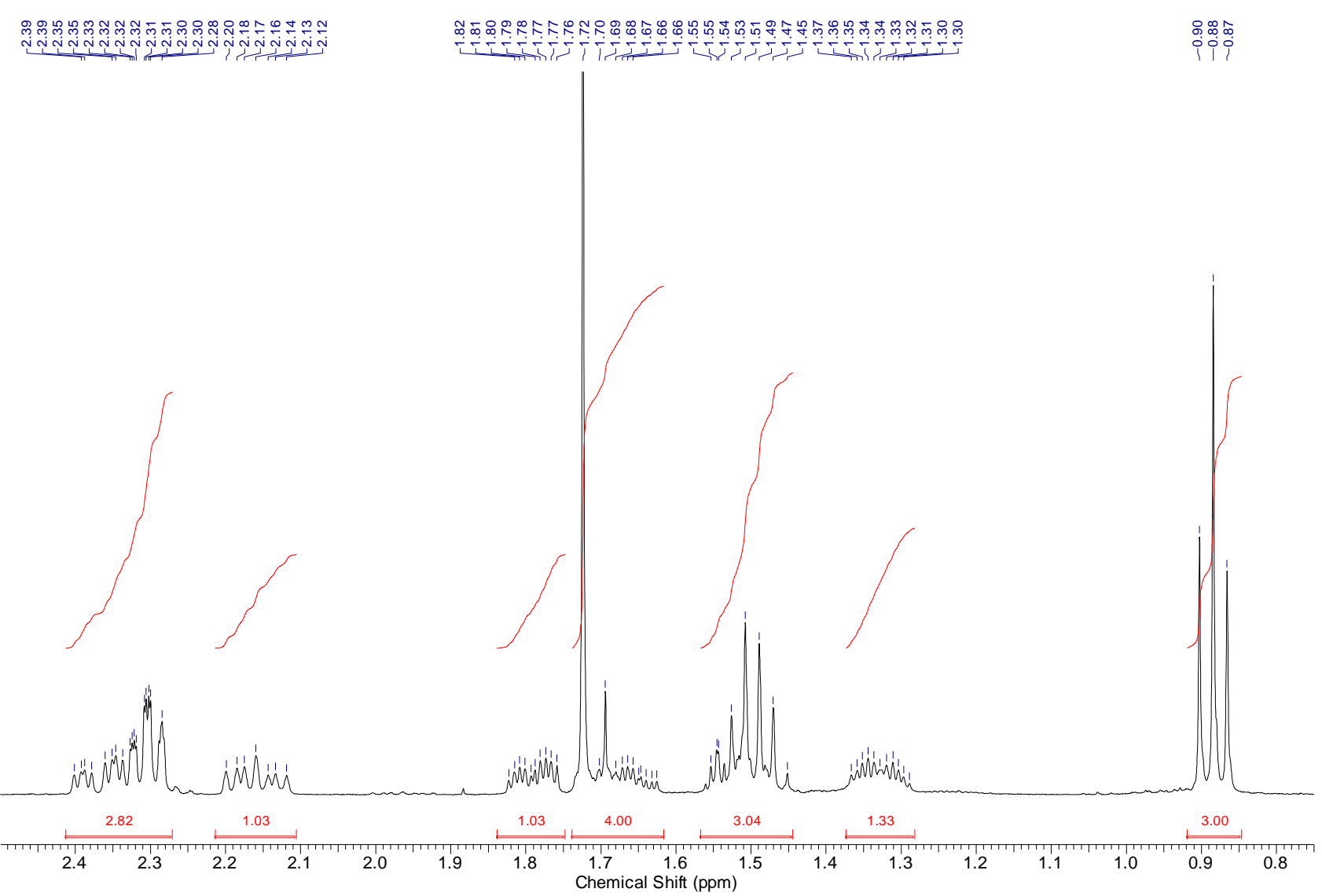

${ }^{1} \mathrm{H} \mathrm{NMR}(400 \mathrm{MHz})$ spectrum of acetate 16 in $\mathrm{C}_{6} \mathrm{D}_{6}(0.75-2.5 \mathrm{ppm})$ 


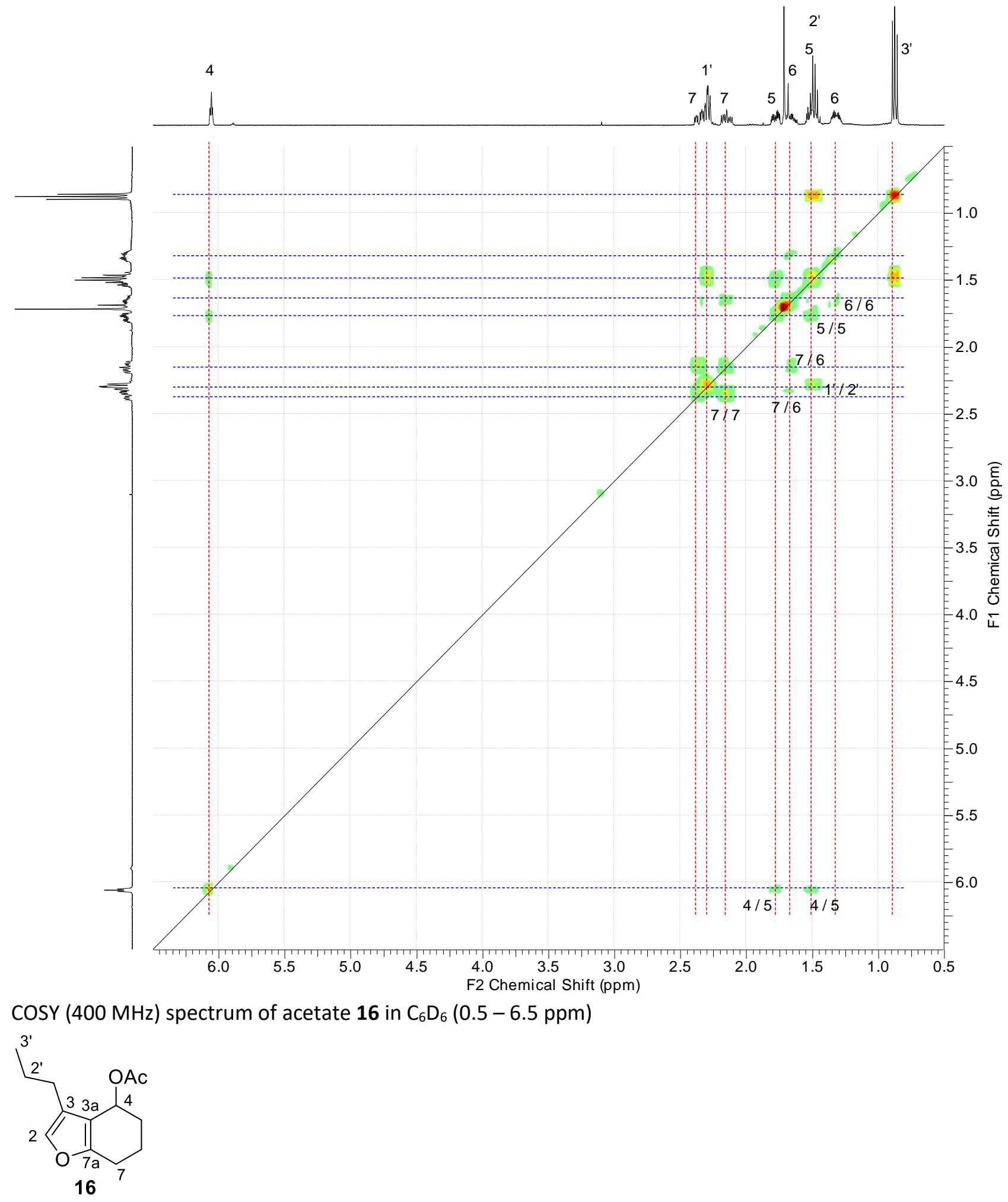




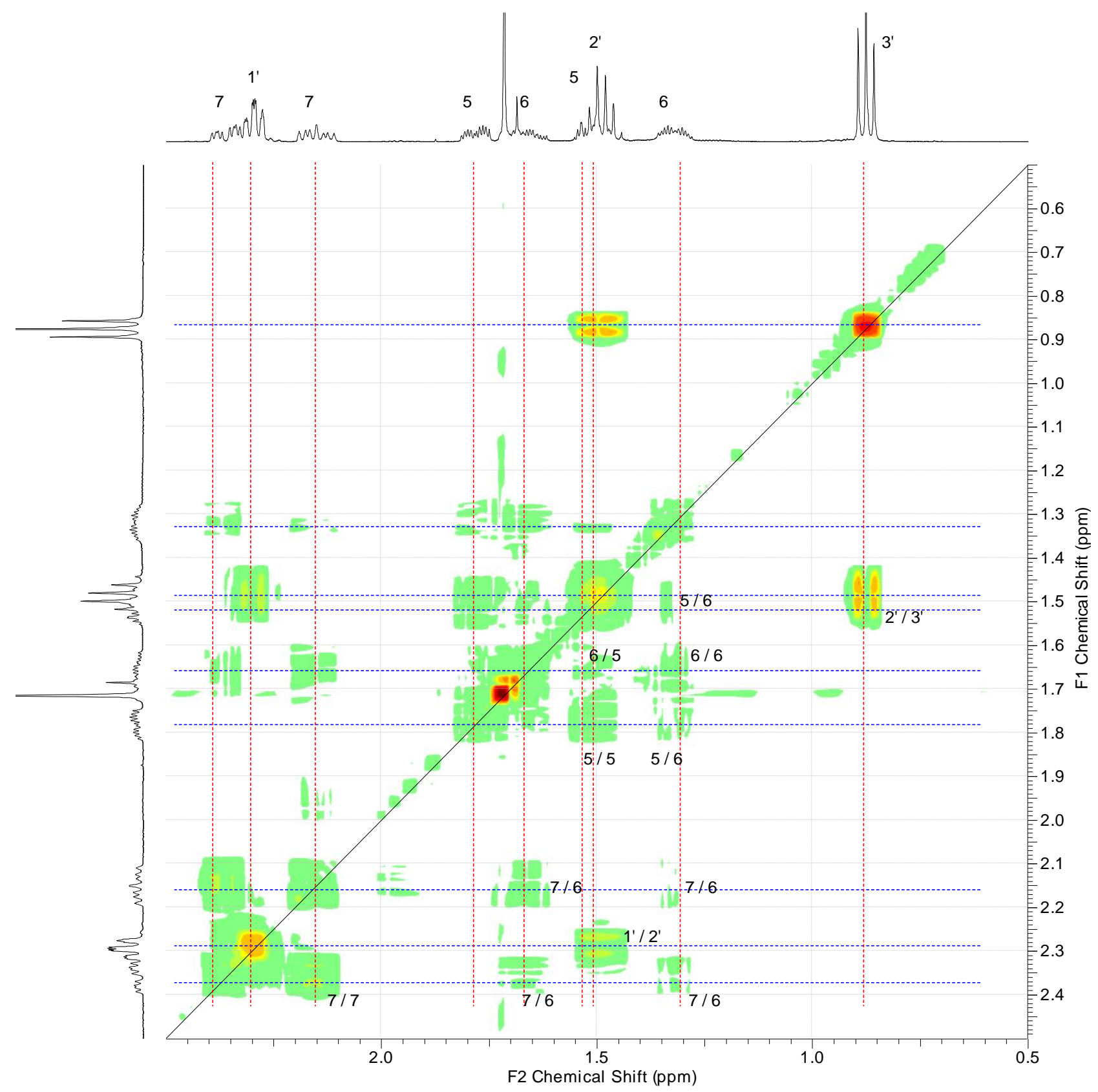

$\operatorname{COSY}(400 \mathrm{MHz})$ spectrum of acetate 16 in $\mathrm{C}_{6} \mathrm{D}_{6}(0.5-2.5 \mathrm{ppm})$

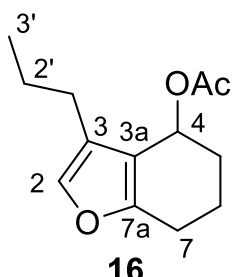

16 


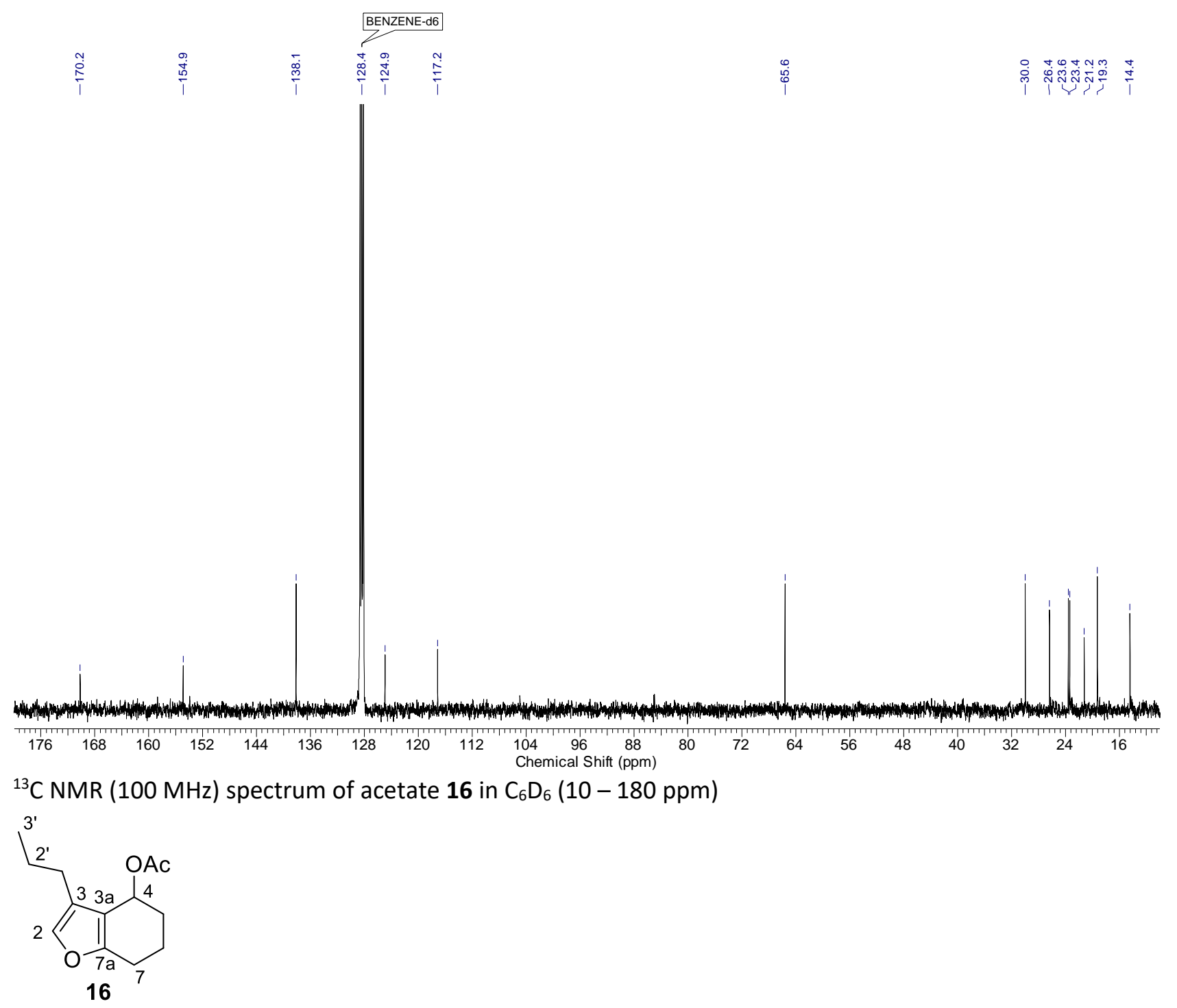




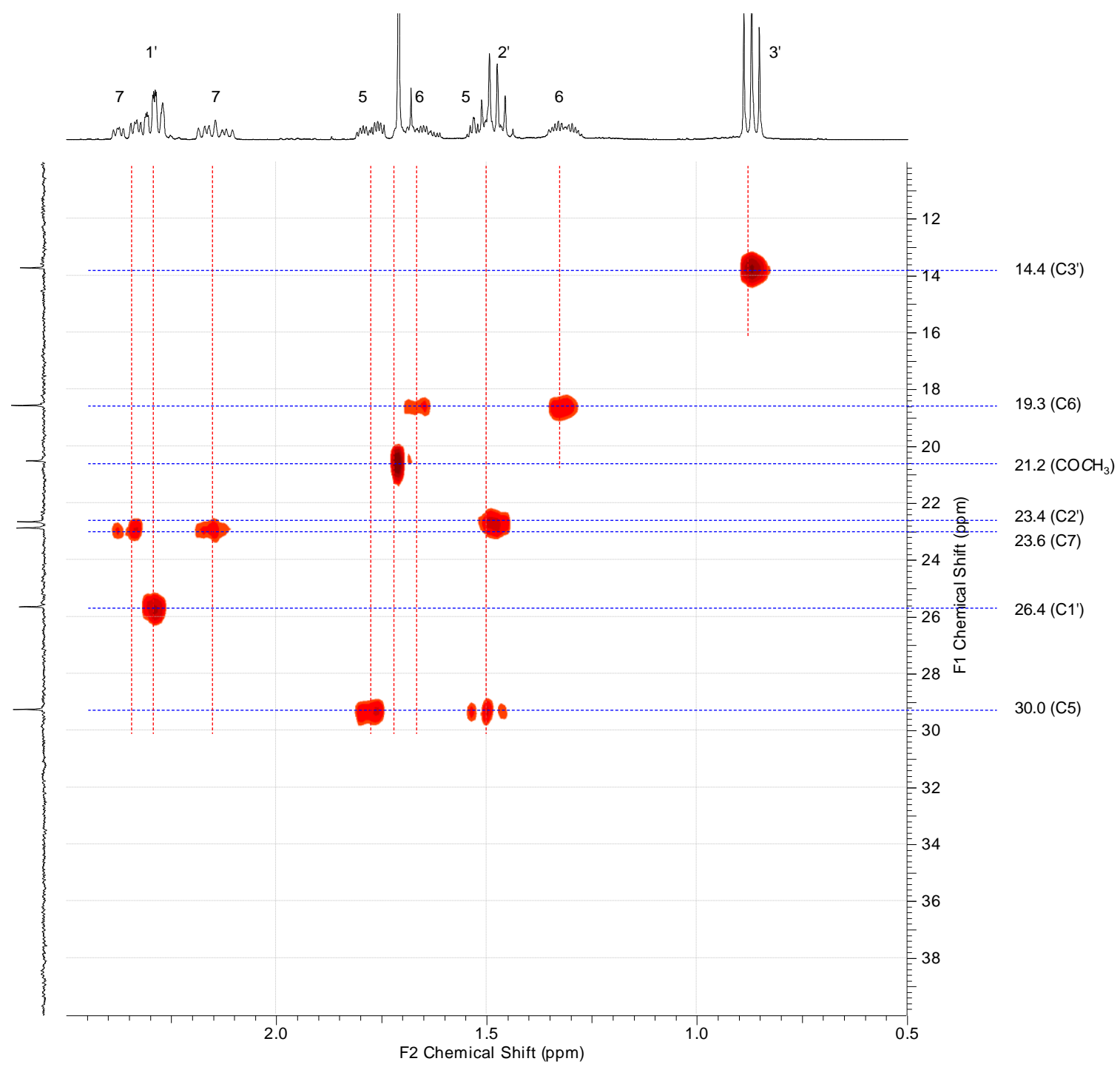

HSQC spectrum of acetate 16 in $\mathrm{C}_{6} \mathrm{D}_{6}(0.5-2.5,10-40 \mathrm{ppm})$

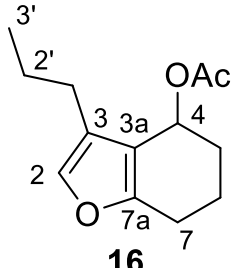




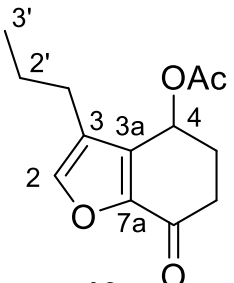

19

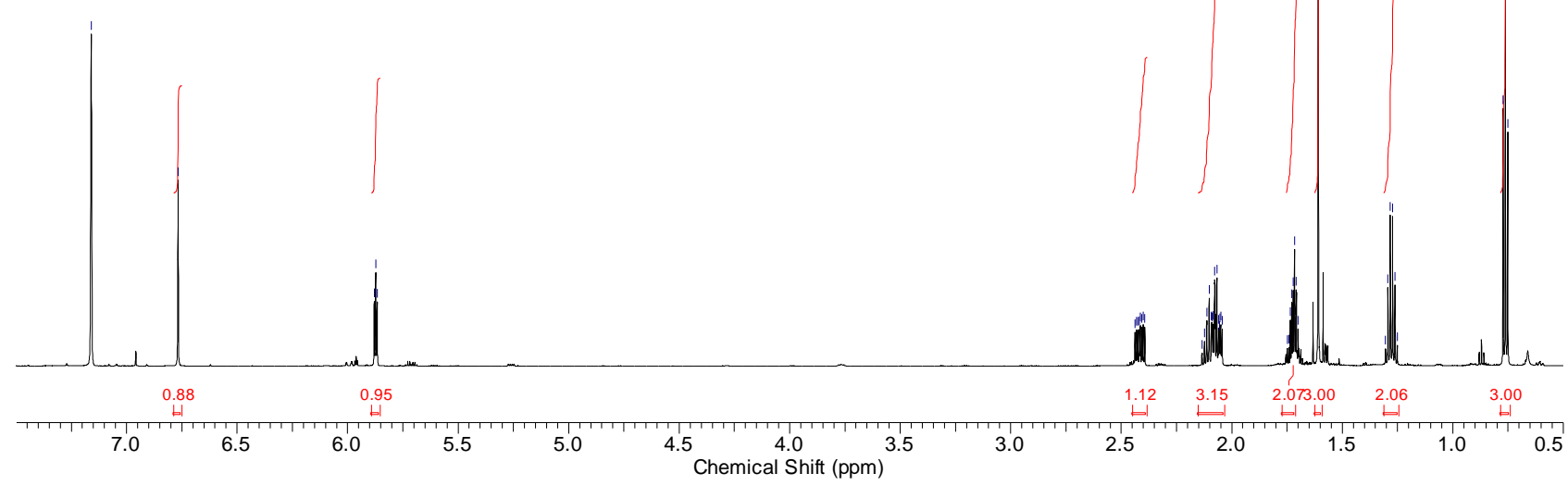

${ }^{1} \mathrm{H} \mathrm{NMR}(400 \mathrm{MHz})$ spectrum of acetate 19 in $\mathrm{C}_{6} \mathrm{D}_{6}(0.5-7.5 \mathrm{ppm})$

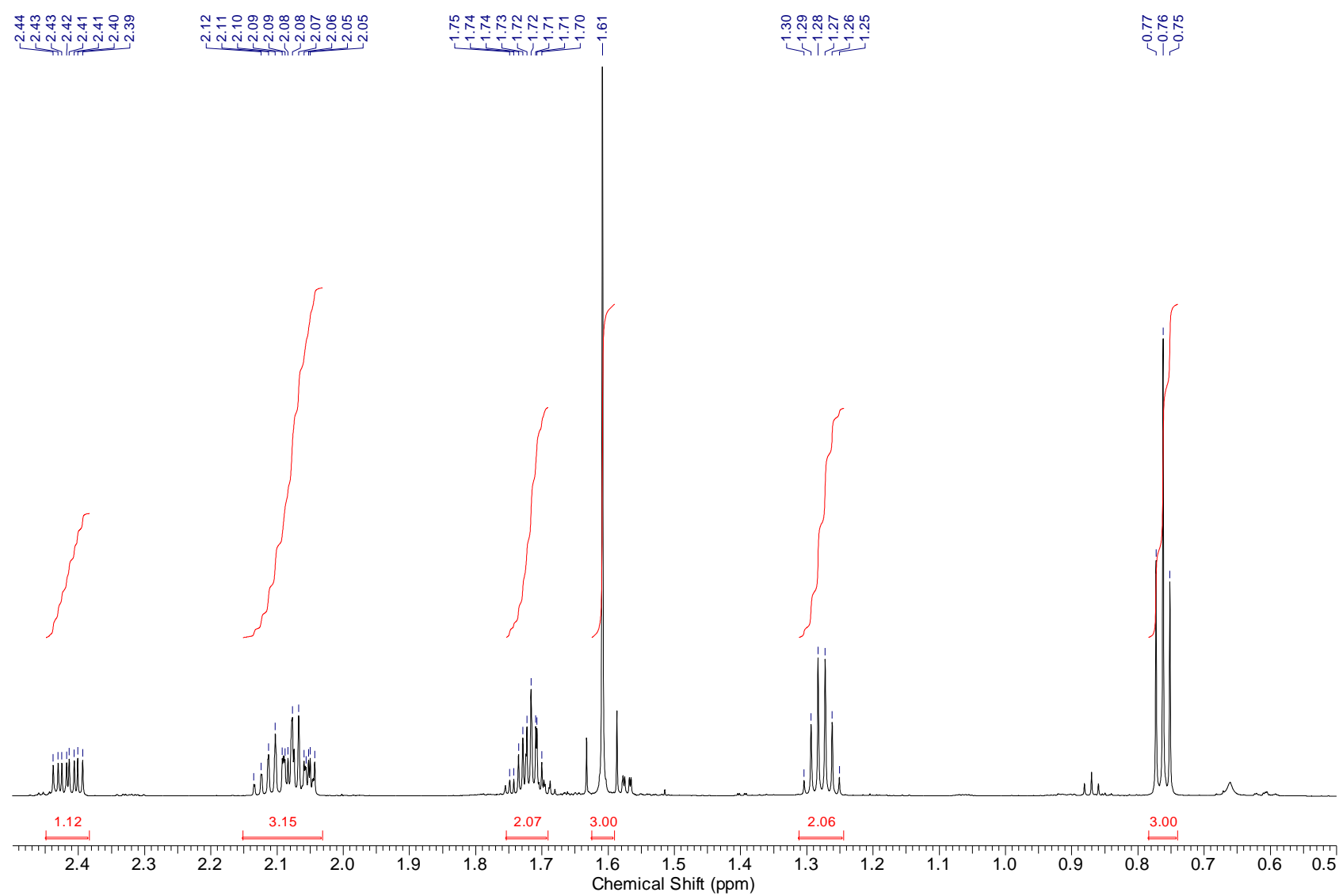

${ }^{1} \mathrm{H}$ NMR $(400 \mathrm{MHz})$ spectrum of acetate 19 in $\mathrm{C}_{6} \mathrm{D}_{6}(0.5-2.5 \mathrm{ppm})$ 


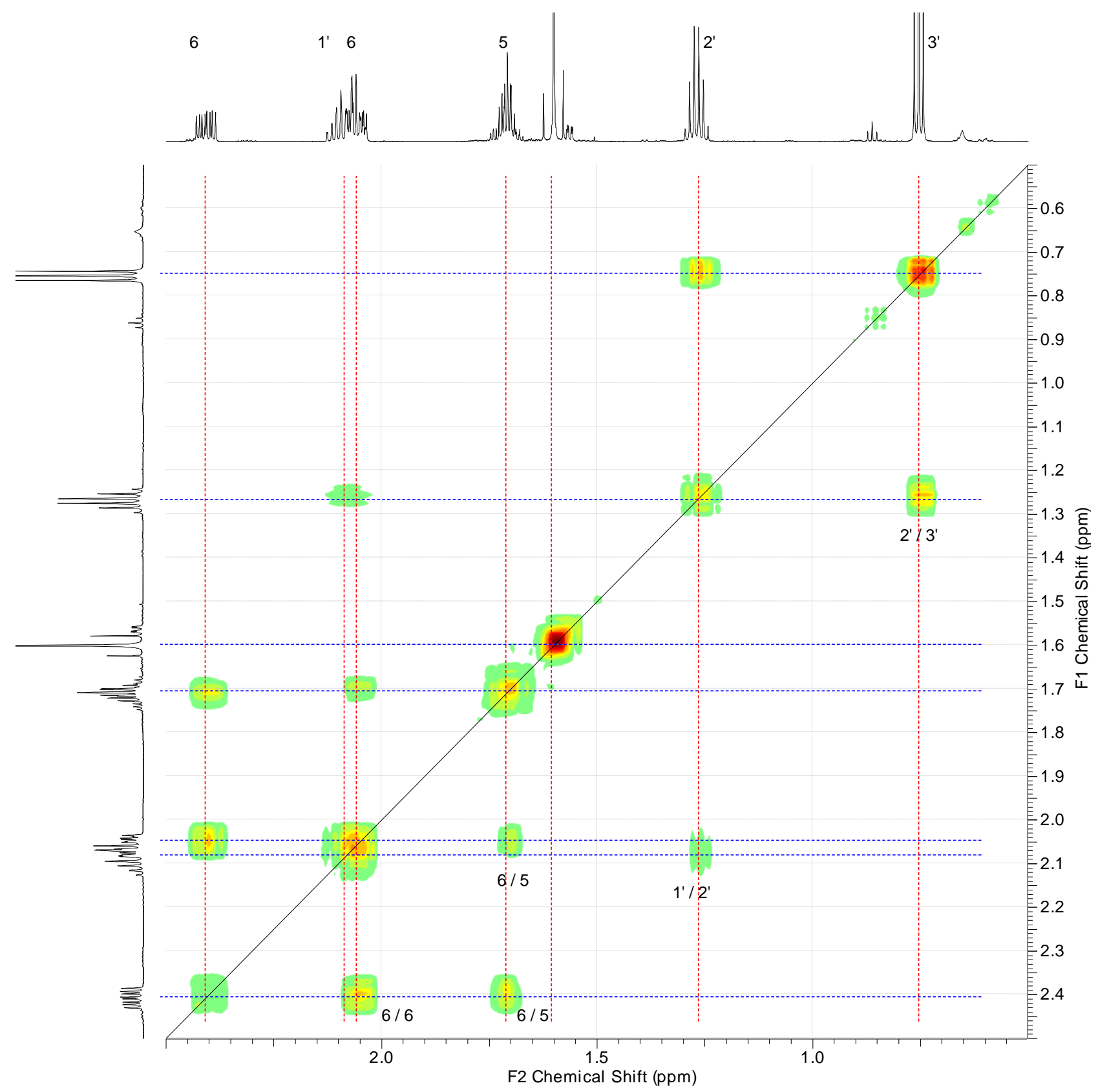

$\operatorname{COSY}(400 \mathrm{MHz})$ spectrum of acetate 19 in $\mathrm{C}_{6} \mathrm{D}_{6}(0.5-2.5 \mathrm{ppm})$

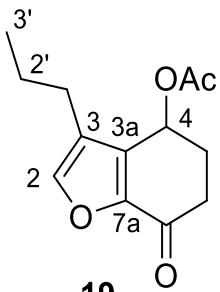




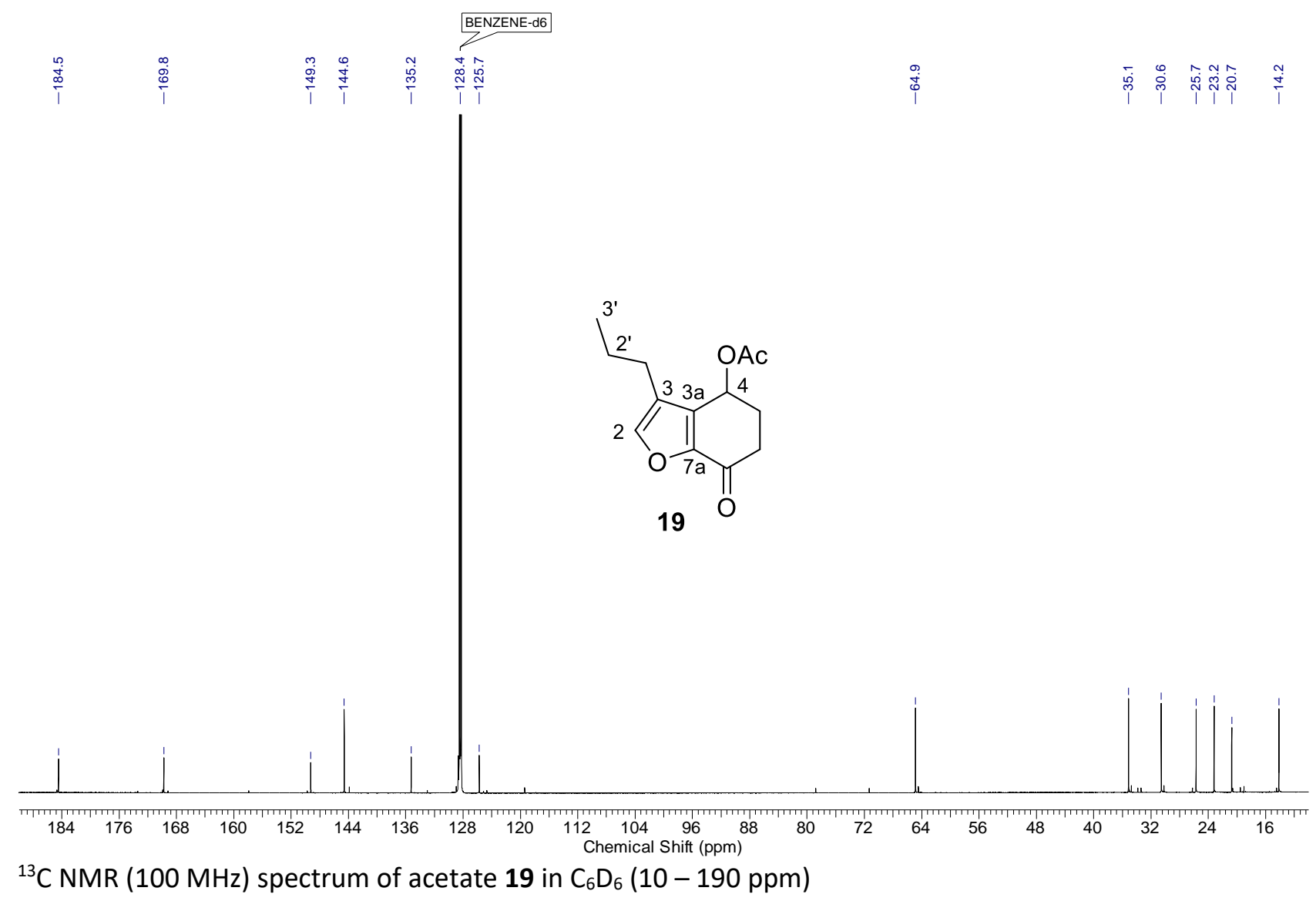




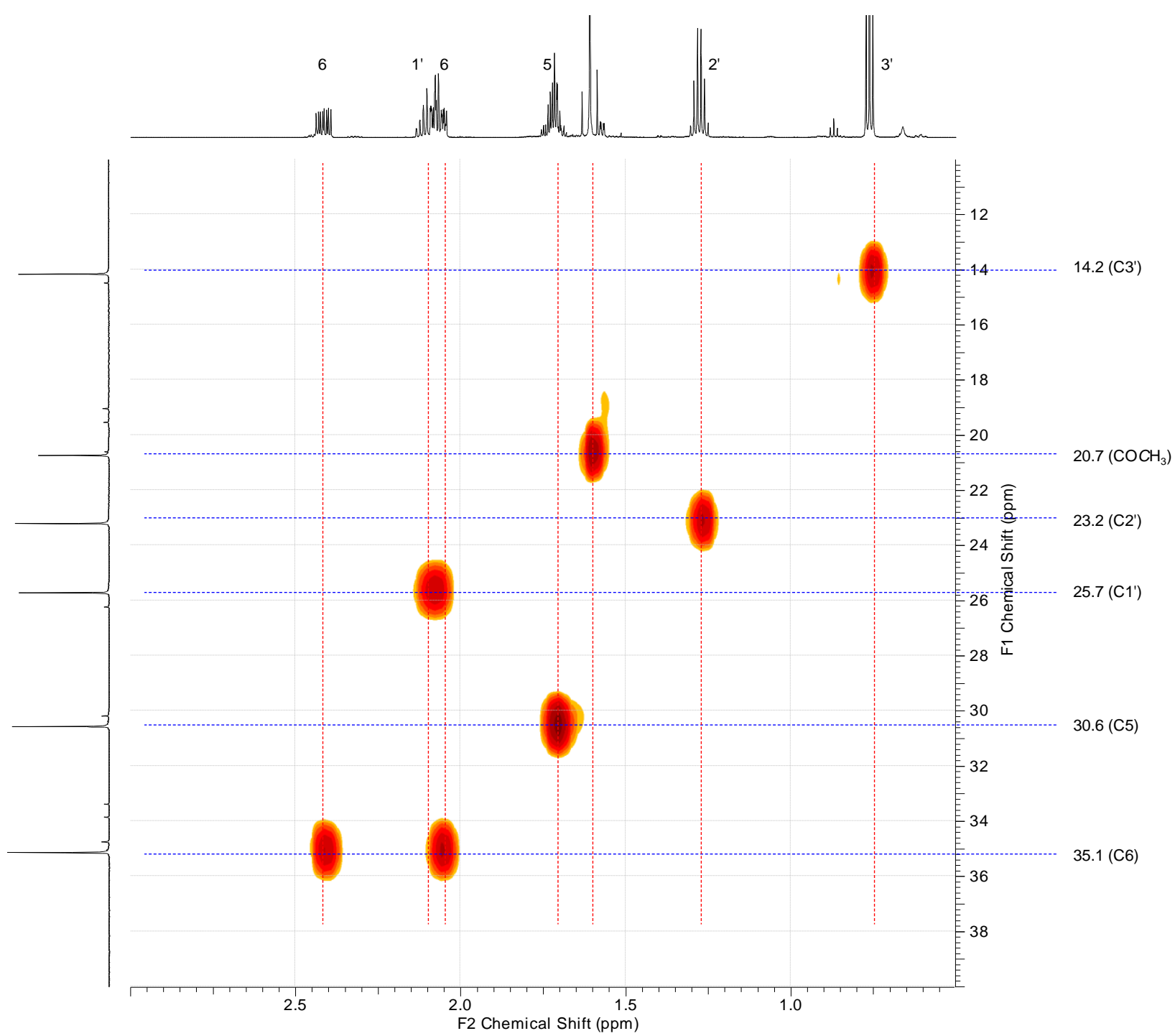

HSQC spectrum of acetate 19 in $\mathrm{C}_{6} \mathrm{D}_{6}(0.5-3.0,10-40 \mathrm{ppm})$

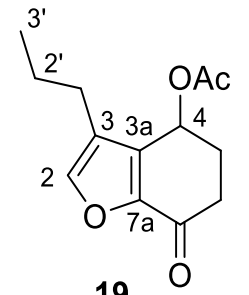




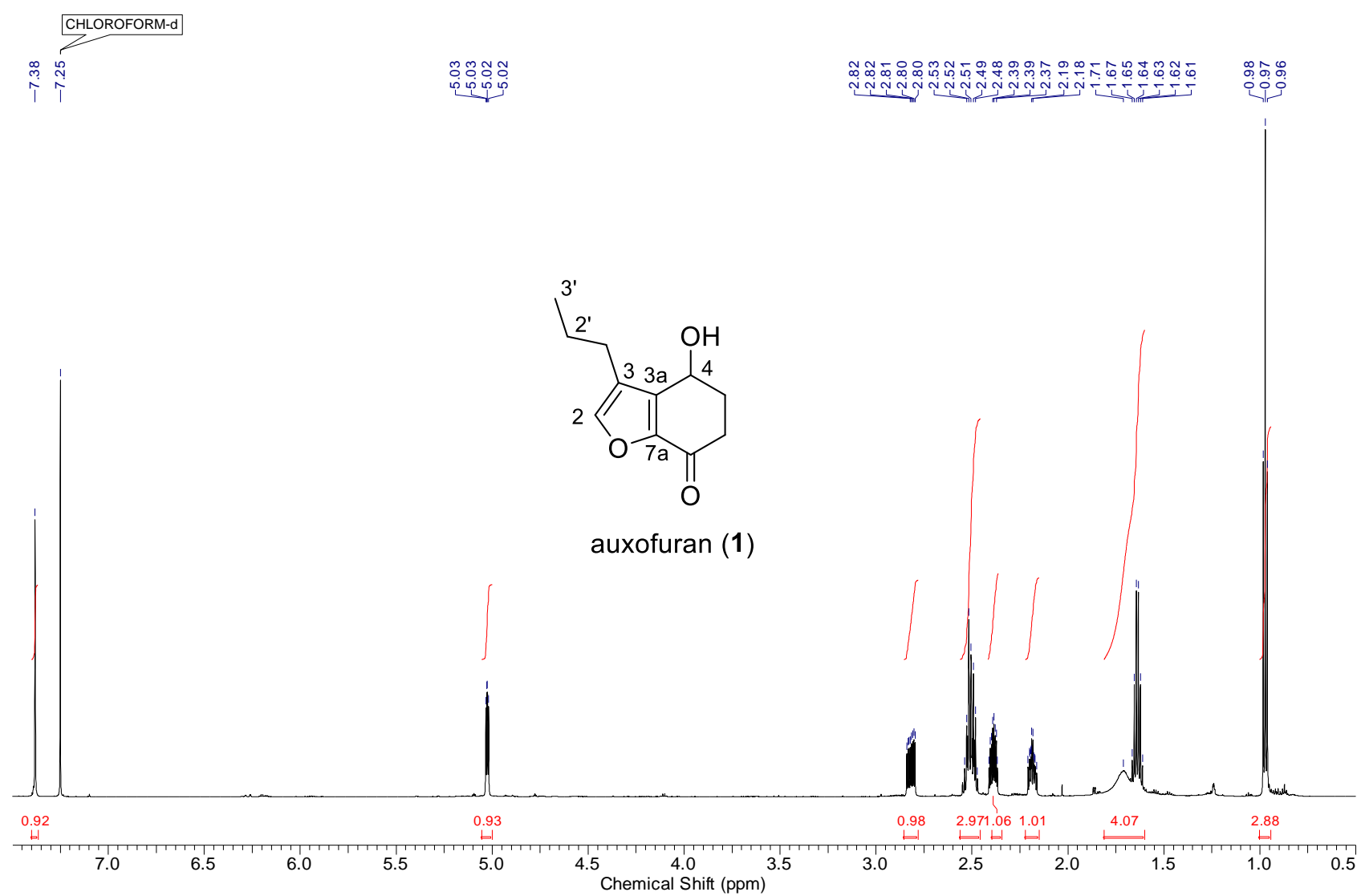

${ }^{1} \mathrm{H} \mathrm{NMR} \mathrm{(400} \mathrm{MHz)} \mathrm{spectrum} \mathrm{of} \mathrm{auxofuran} \mathrm{(1)} \mathrm{in} \mathrm{CDCl}_{3}(0.5-7.5 \mathrm{ppm})$

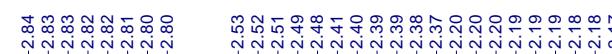

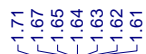

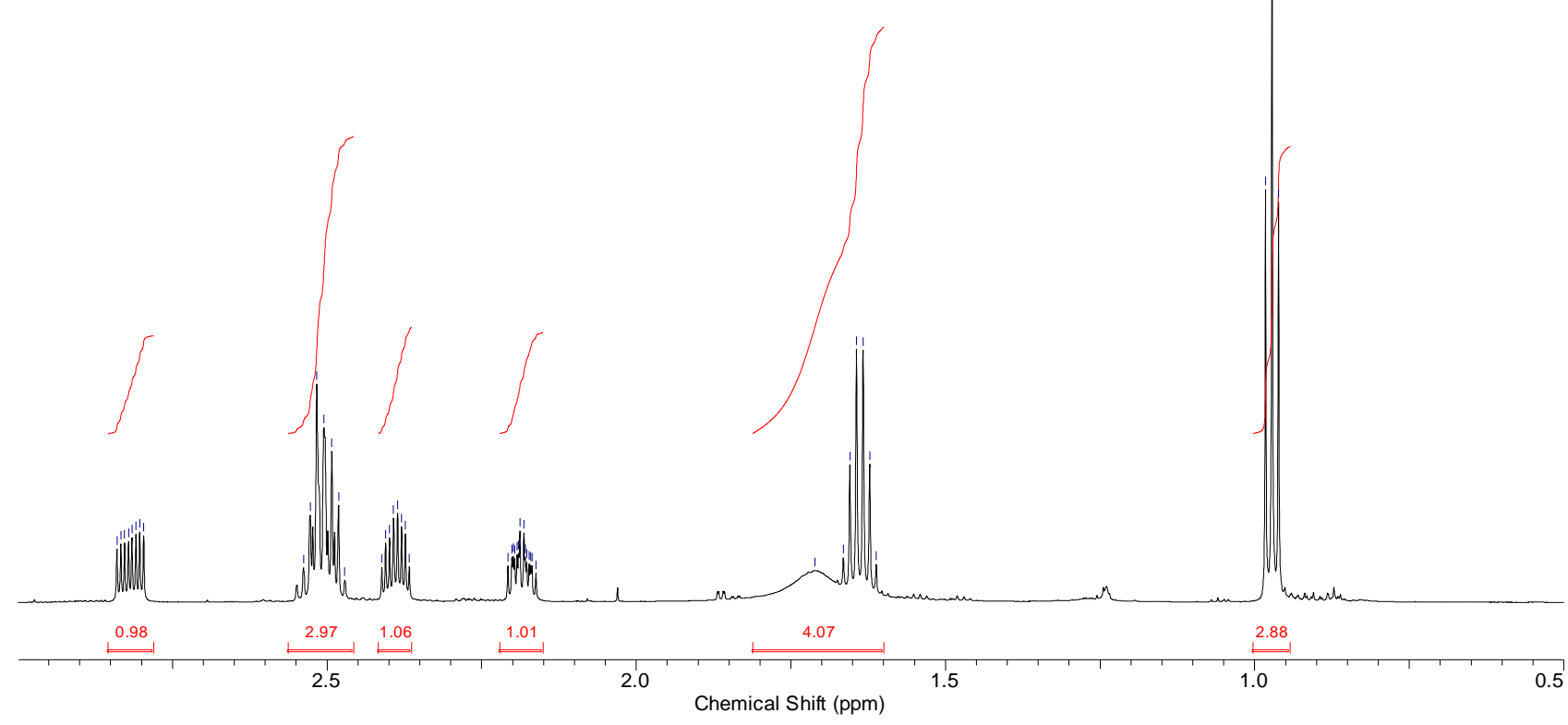

${ }^{1} \mathrm{H}$ NMR $(400 \mathrm{MHz})$ spectrum of auxofuran $(\mathbf{1})$ in $\mathrm{CDCl}_{3}(0.5-7.5 \mathrm{ppm})$ 


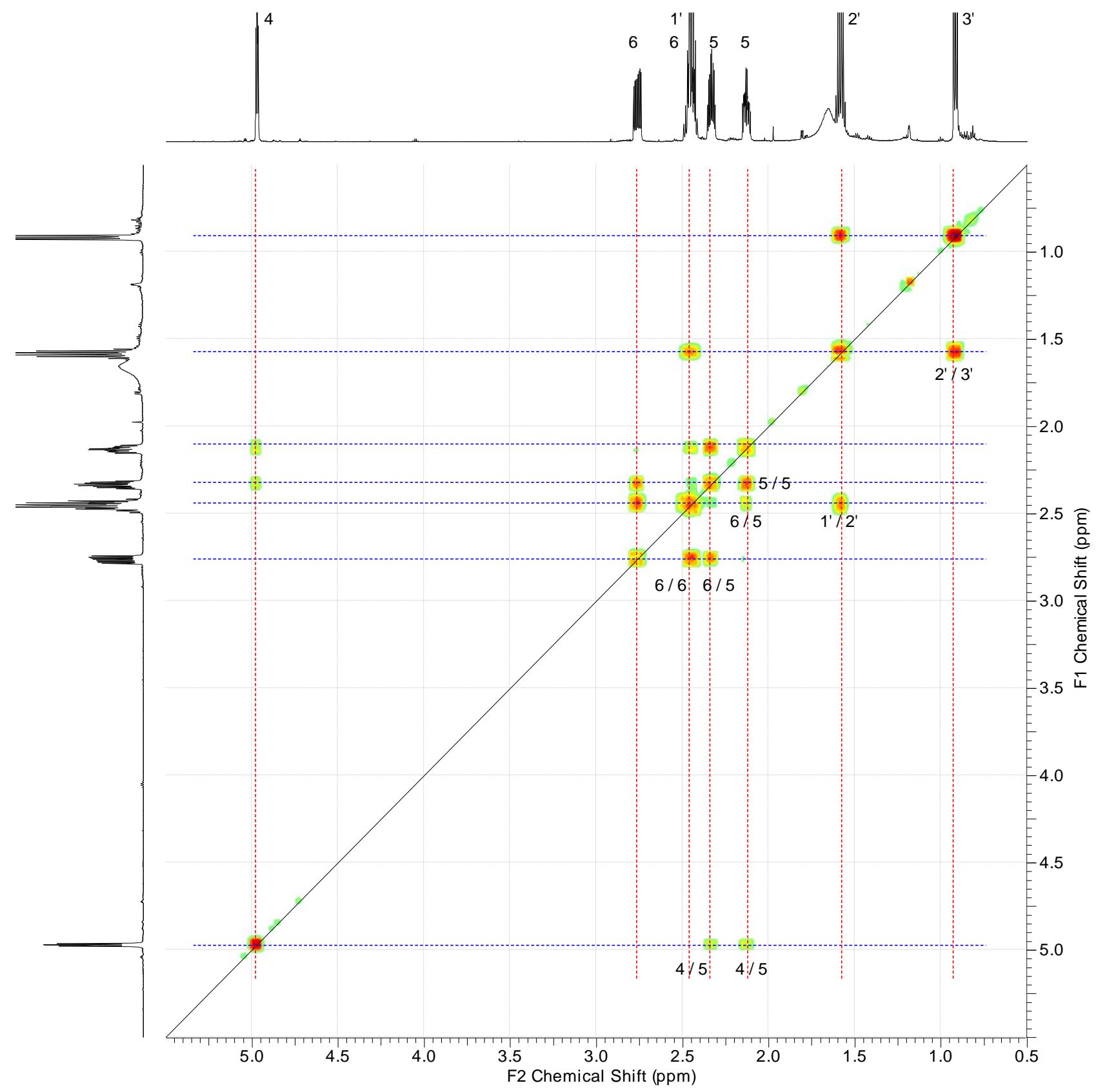

$\operatorname{COSY}(400 \mathrm{MHz})$ spectrum of auxofuran (1) in $\mathrm{CDCl}_{3}(0.5-5.5 \mathrm{ppm})$

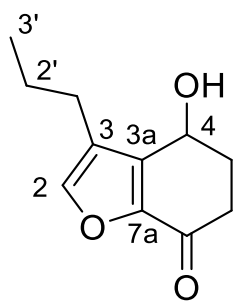

auxofuran (1) 


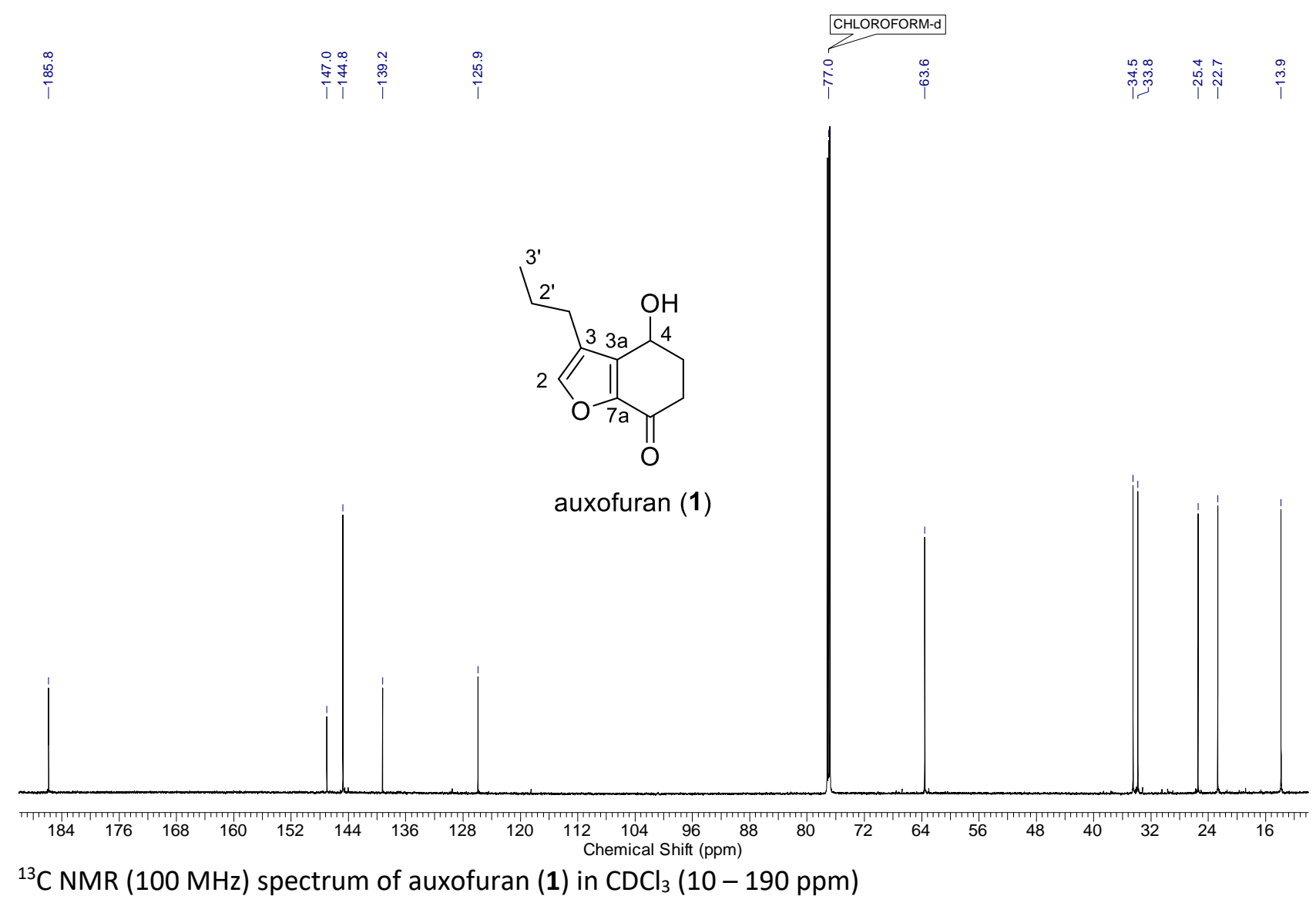




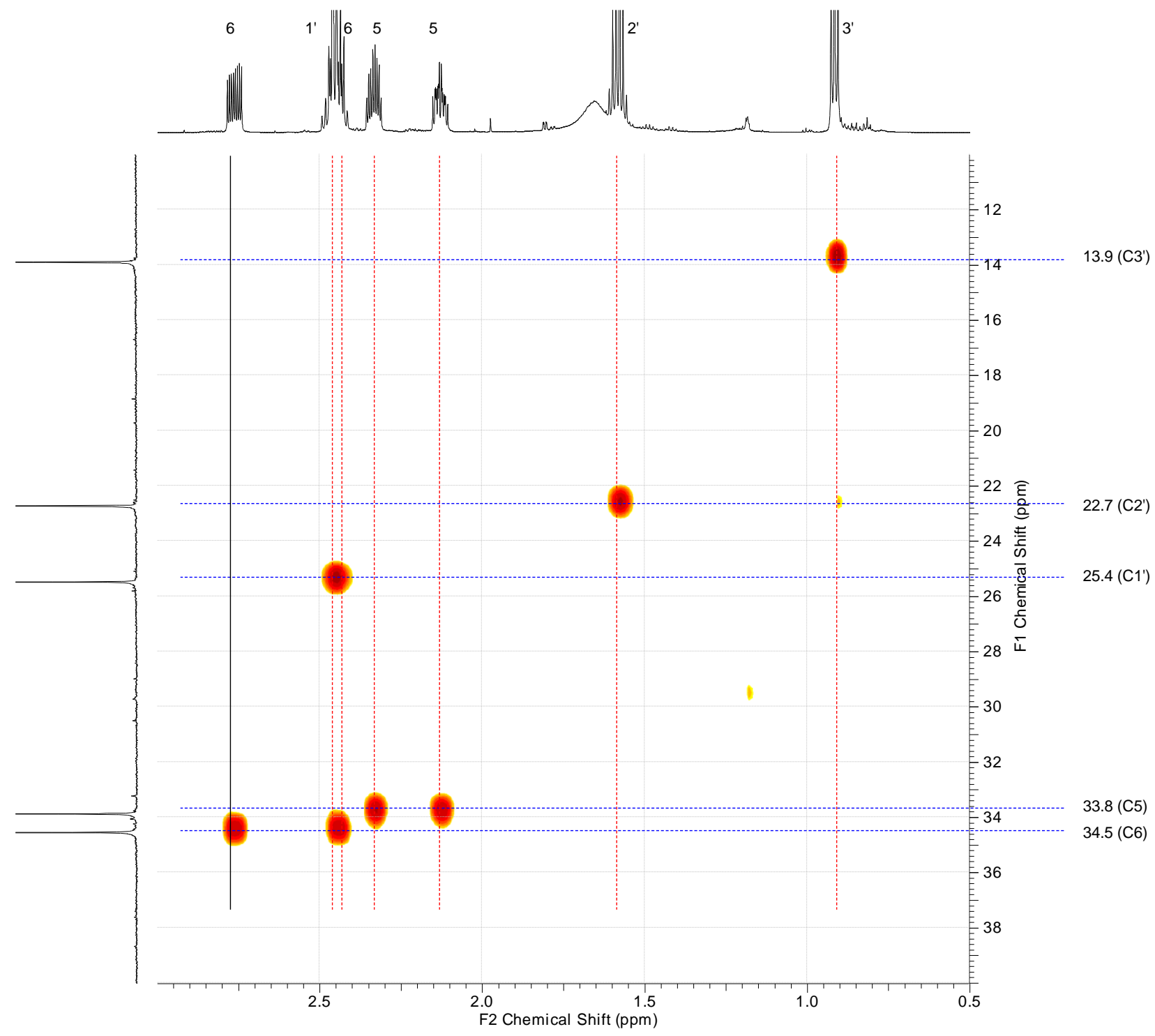

HSQC spectrum of auxofuran (1) in $\mathrm{CDCl}_{3}(0.5-3.0,10-40 \mathrm{ppm})$

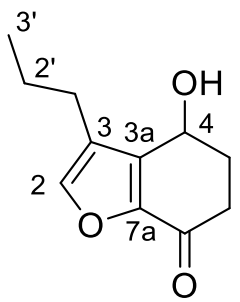

auxofuran (1) 


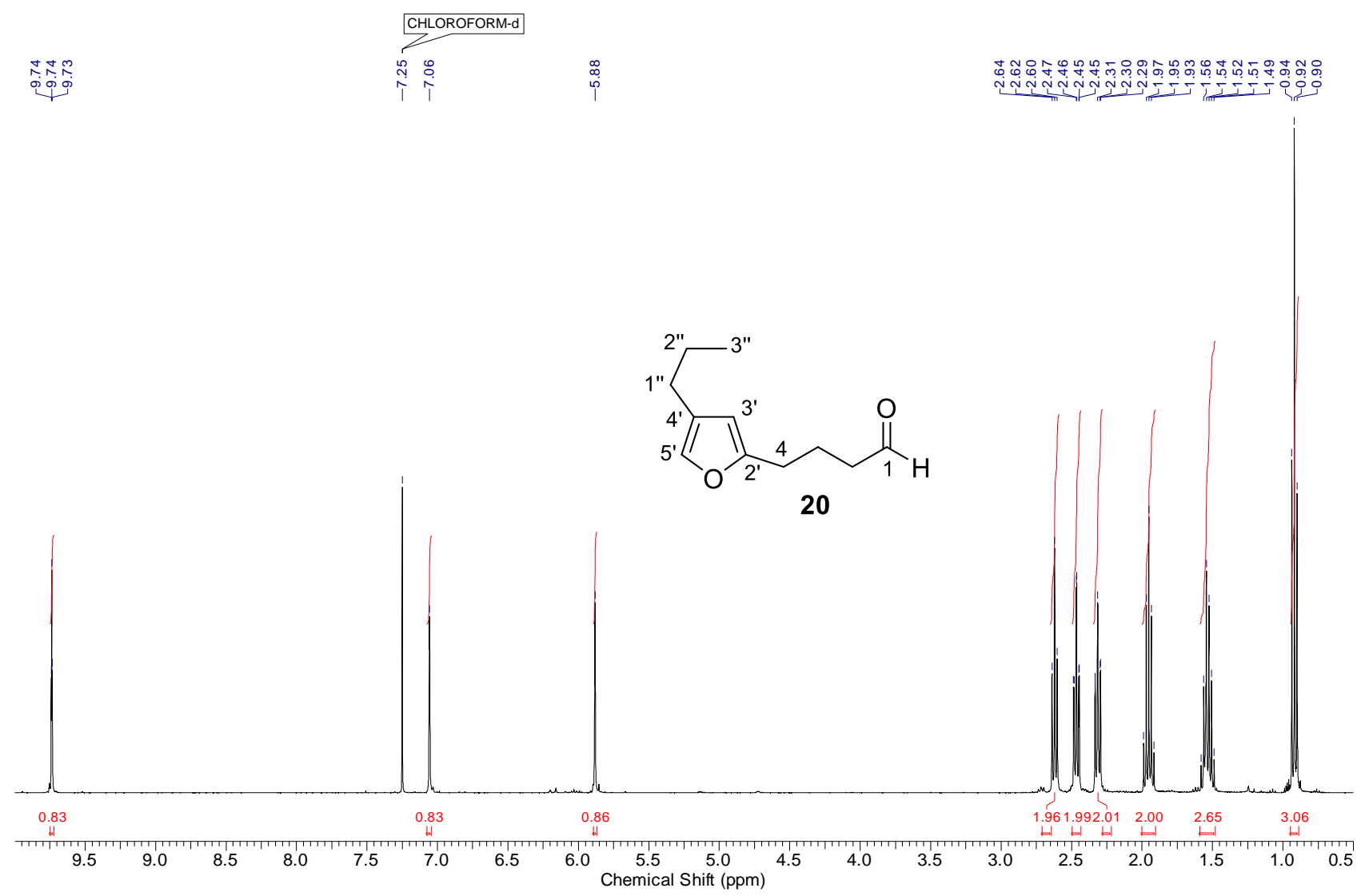

${ }^{1} \mathrm{H} \mathrm{NMR}(400 \mathrm{MHz})$ spectrum of aldehyde 20 in $\mathrm{CDCl}_{3}(0.5-10.0 \mathrm{ppm})$

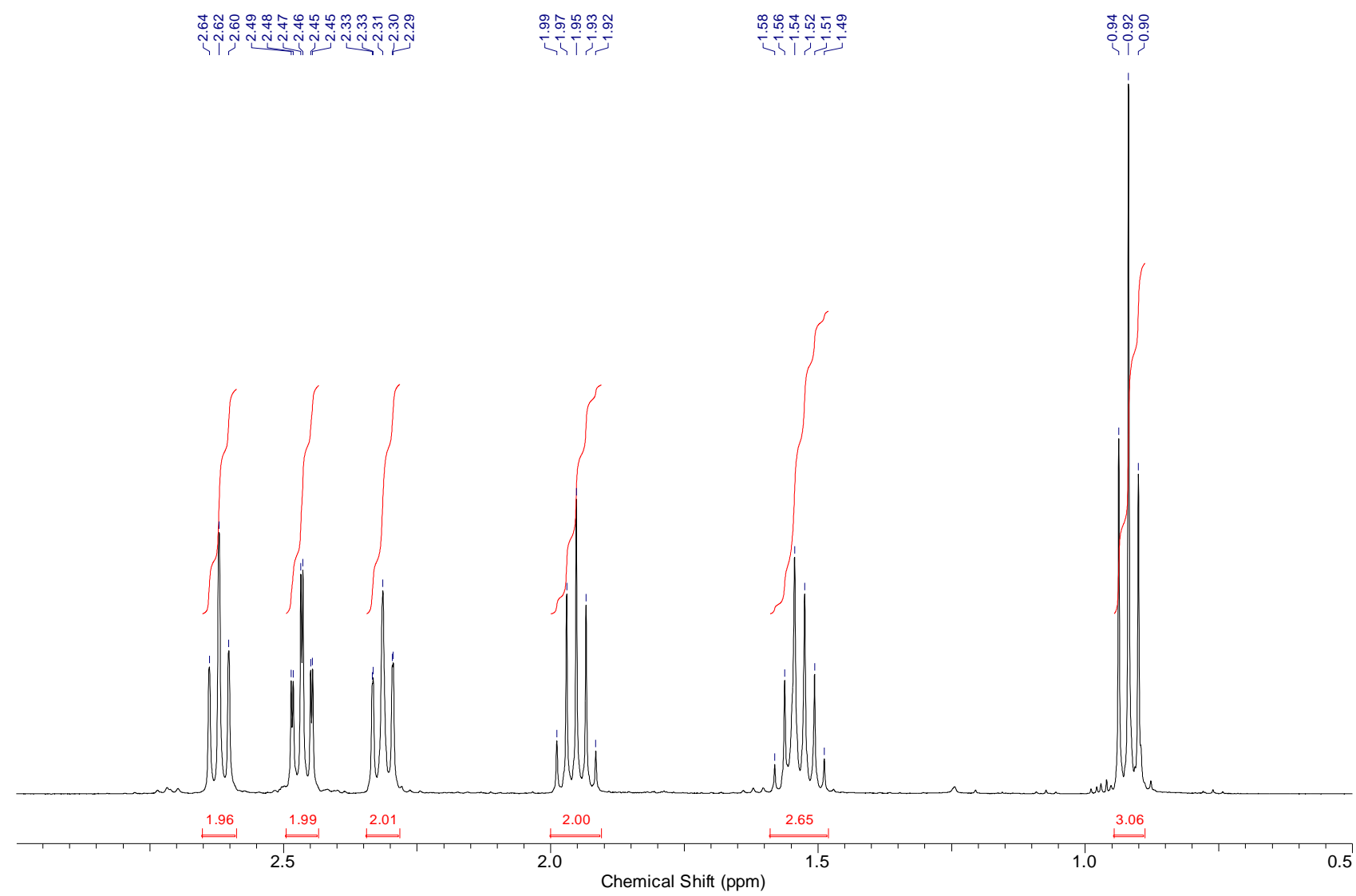

${ }^{1} \mathrm{H} \mathrm{NMR}(400 \mathrm{MHz})$ spectrum of aldehyde 20 in $\mathrm{CDCl}_{3}(0.5-3.0 \mathrm{ppm})$ 


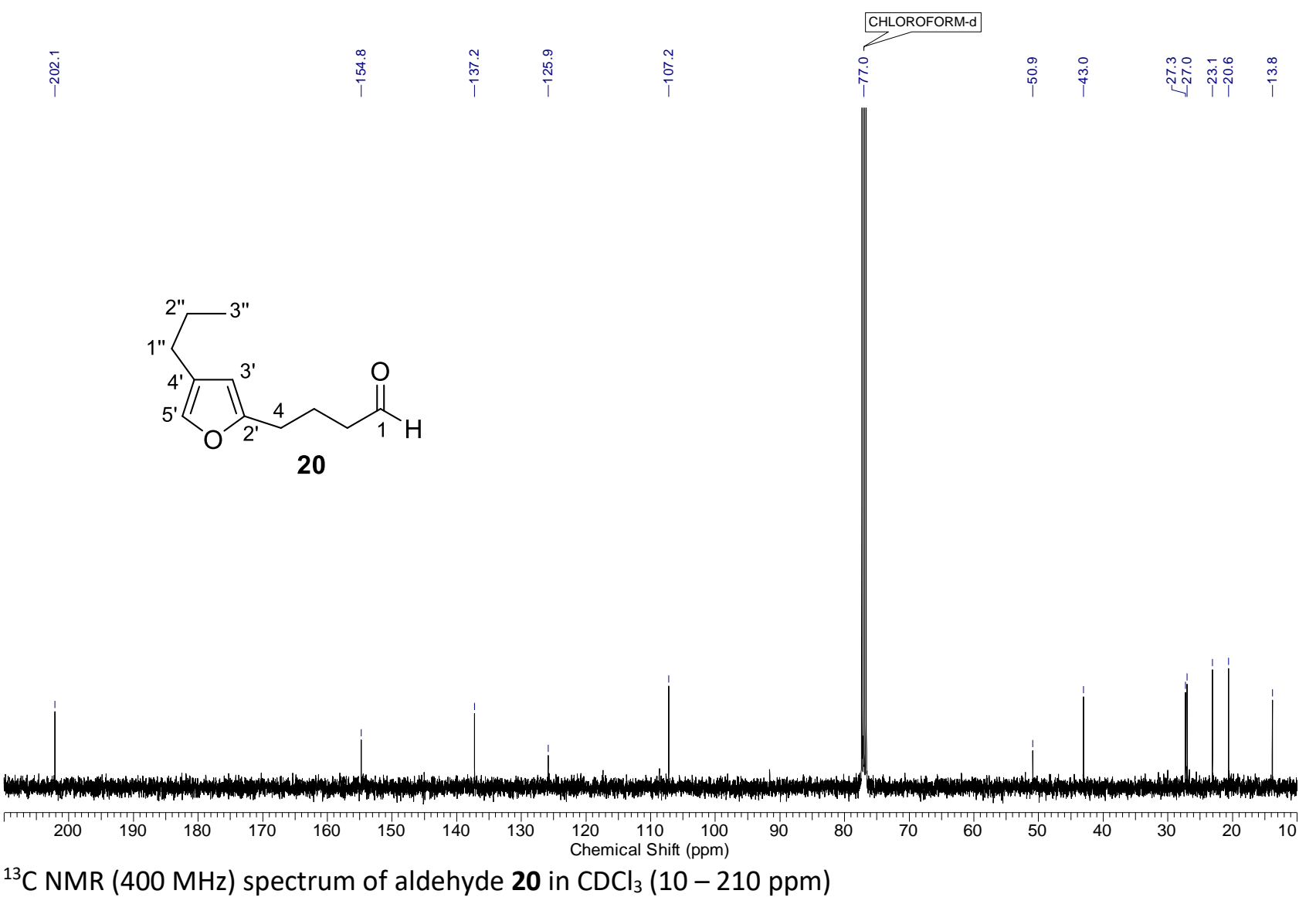

